\title{
A Numerical Investigation of Gap and Shape Effects on a 2D Plunger-Type Wave Maker
}

\section{Nikseresht, Amir H.; Bingham, Harry B.}

Published in:

Journal of Marine Science and Application

Link to article, DOI:

$10.1007 / \mathrm{s} 11804-020-00135-5$

Publication date:

2020

Document Version

Peer reviewed version

Link back to DTU Orbit

Citation (APA):

Nikseresht, A. H., \& Bingham, H. B. (2020). A Numerical Investigation of Gap and Shape Effects on a 2D Plunger-Type Wave Maker. Journal of Marine Science and Application, 19, 101-115.

https://doi.org/10.1007/s11804-020-00135-5

\section{General rights}

Copyright and moral rights for the publications made accessible in the public portal are retained by the authors and/or other copyright owners and it is a condition of accessing publications that users recognise and abide by the legal requirements associated with these rights.

- Users may download and print one copy of any publication from the public portal for the purpose of private study or research.

- You may not further distribute the material or use it for any profit-making activity or commercial gain

- You may freely distribute the URL identifying the publication in the public portal

If you believe that this document breaches copyright please contact us providing details, and we will remove access to the work immediately and investigate your claim. 


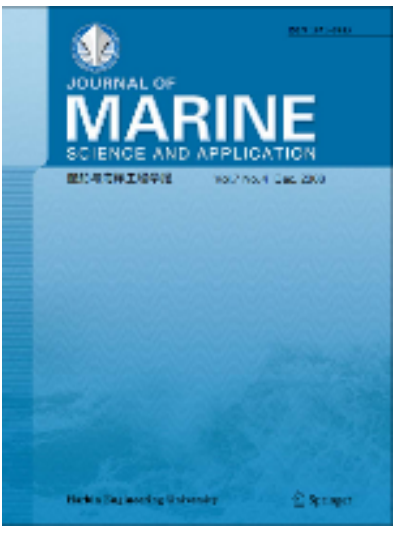

\section{A Numerical Investigation of gap and shape effects around a 2D plunger-type wavemaker}

\begin{tabular}{|r|l|}
\hline Journal: & Journal of Marine Science and Application \\
\hline Manuscript ID & JMSA-2019-06-0051 \\
\hline Manuscript Type: & Original Article \\
\hline Keywords: & Wave-maker, Plunger-type, Gap, Dynamic mesh, VOF \\
\hline \multicolumn{2}{|l}{} \\
\end{tabular}

\section{SCHOLARONE ${ }^{\text {W }}$ \\ Manuscripts}




\title{
A Numerical Investigation of gap and shape effects around a 2D plunger-type wavemaker
}

\begin{abstract}
Plunger-type wave makers installed in experimental tanks will generally include a gap between the back of the wedge and the wall of the tank. In this paper we study the influence of this gap on the wave making the performance of the plunger, using 2D CFD calculations for a range of nearly linear wave conditions and compare the present results with experiments and linear potential theory. Also, three wedge profile shapes are considered in a constant submerged volume, and the generated waves are compared to the predictions of linear potential flow theory. The calculations are made using the commercial ANSYS-FLUENT finite volume code to solve the Navier-Stokes equations using dynamic meshes and a Volume of Fluid (VOF) scheme to capture the air-water interface. The linear potential flow solution of $\mathrm{Wu}$ (1988) is also extended to treat wedge shapes of arbitrary profile to serve as a reference solution. The amplitude ratios of the generated waves predicted by the CFD calculations compare very well with the predictions of potential flow theory, but the indicating that potential flow can predict well this ratio for small amplitude motions in 2D. Significant higher harmonic components are however produced by larger amplitude motions.
\end{abstract}

\section{Keywords:}

Wave-maker, Plunger-type, Gap, Dynamic mesh, VOF

\section{Introduction}

There are two basic types of wave-makers, which are used in laboratories. The most commonly used type of wave-maker is the piston type which generates waves by an oscillatory motion in the direction of wave propagation. Also, most of the viscous analysis have been done on the piston type wave-makers [1]. Plunger-type devices, where a floating body is oscillated vertically, are often used to generate waves in experimental facilities. In contrast to piston- and flap-type wavemakers, analytic solutions are not available for the plunger-type wavemaker, but a number of numerical solutions have been presented in the literature, based on both potential flow theory and the NavierStokes equations. Linear solutions via eigen-function expansion were obtained by Wang [2] and $\mathrm{Wu}$ [3]. Two-dimensional (2D) linear numerical solutions were also presented by $\mathrm{Wu}$ [4] who used 
the Boundary Element Method (BEM), and by Arcari [5] using a finite difference method. Nonlinear BEM solutions were obtained by Kashiwagi [6] and by Koo and Kim [7], both showing very good agreements with experimental measurements. Mikkola [8, 9] used a finite volume Navier-Stokes solver, but neglected viscous effects. Yim et al. [10] validated a RANS model by comparing numerical results with experimental data involving wave generation by dropping a rigid body at various heights into a 2D flume partially filled with water. Elangovan and Lal. [11, 12] and Gadelho et al. [13] solved the Navier stokes equations for a triangular plunger-type wave maker. Yeung and Jiang [14] investigated shape effects on the viscous damping and the motion of a heaving cylinder using a random-vortex method. Madhi et al. [15] applied both nonlinear potential flow and viscous-flow solutions using a random vortex method to the "Berkeley Wedge" profile and compared the results to experimental measurements. Also Azadian-Kharenjani et. al. [16] applied a nonlinear viscous flow to understand the effect of wedge shape on the generated wave quality in a constant submerged body.

In all of the above mentioned work, the wedge was either placed far from the tank wall or sliding along the wall with no gap between the back of the wedge and the tank wall. For most real installations, there will be a finite gap between the wedge and the tank wall, and one of the goal of this study is to consider the effect of this gap on the resultant wave. We also investigate the performance of two alternative profiles compared to the simple wedge. Calculations are made using the ANSYS-FLUENT 16 CFD software with dynamic grids near the moving wedge and a Volume of Fluid (VOF) scheme to capture the air-water interface. A series of small amplitude conditions (wave height divided by wave length less than about 0.03 ) are run and the results are found to compare very well with the linear potential flow theory, indicating that viscous effects are negligible for small amplitude motions. Some larger amplitude cases are also run, leading to significant higher-harmonic generation which is consistent with previous findings. The higherharmonic generation is found to be larger for the alternative profiles compared to the simple wedge. 


\section{Problem definition}

In Figure 1, a 2D section of the wedge wave maker is shown.

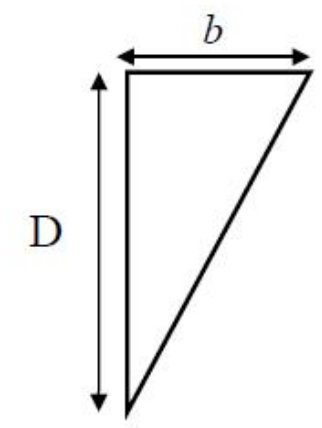

Figure 1: 2D section of the float, DTU wedge

The flume at the Technical University of Denmark (DTU) which the experiments are done on it is $28 \mathrm{~m}$ long $\times 0.6 \mathrm{~m}$ wide and $0.8 \mathrm{~m}$ deep. The dimensions of the wedge have been chosen based on two constraints. First, the device has to generate waves whose amplitudes approach the breaking wave limit. The Battjes breaking wave criteria for deep water waves states the maximum height of a stable wave $H_{\max }$ as a function of the wave length $\lambda: H_{\max }=0.14 \lambda$, [5]. As the first constraint, the breaking wave conditions should remain inside the tank for the target range of wave periods, $T$. As a second constraint, it should generate intermediate and deep-water waves, which means $\frac{2 \pi h}{g T^{2}} \geq 0.05$, [5] where $h$ is the water depth and $g$ the gravitational acceleration.

With the above constraints, the water depth is set to $0.65 \mathrm{~m}$, the draft of the wedge is fixed to $D=0.45 \mathrm{~m}$ and the clearance value, equivalent to the maximum stroke amplitude, is $S_{\max }=0.2 \mathrm{~m}$. Finally, based on the initial study of [5], the wedge breath is set to $b=0.225$ $m$. Table 1 summarizes the limits of the preliminary parameters of the wedge and waves. The values $h, \mathrm{~b}, D$ and $S_{\max }$ are kept constant throughout the study. $\lambda_{\max }$ and $\lambda \min$ are the wave lengths of the longest and shortest target frequencies. The target frequencies cover an interval of intermediate and deep water waves for this tank.

Table 1 : Preliminary parameters of the wedge and waves [5].

\begin{tabular}{|l|l|l|l|l|l|l|}
\hline$h\lceil\mathrm{~m}\rceil$ & $b\lceil\mathrm{~m}\rceil$ & $D\lceil\mathrm{~m}\rceil$ & $S_{\max }\lceil\mathrm{m}]$ & $H_{\max }\lceil\mathrm{m}]$ & $\lambda_{\max }\lceil\mathrm{m}]$ & $\lambda_{\min }\lceil\mathrm{m}\rceil$ \\
\hline 0.65 & 0.225 & 0.45 & 0.2 & 0.28 & 3.06 & 0.5 \\
\hline
\end{tabular}

Because the wedge fills the entire width of the flume, a two-dimensional analysis was performed. Also, two-dimensional wave theory has been used to design the wedge and wedge motion [5]. 
Since this problem is a dynamic problem, the mesh should be changed according to the motion of the wedge, therefore a dynamic mesh is used which can be regenerated at each time step. The domain, which is depicted in Figure 2, is divided into two regions, a re-meshing zone near the wedge with mixed unstructured and structured mesh, and a stationary zone far from the wedge with a structured mesh. For testing the wedge under linear wave conditions, the frequency range of (4 to 12) is chosen and the characteristics of the waves and stroke are shown in Table 2.

Table 2: Test wave conditions

\begin{tabular}{|l|l|l|l|l|l|}
\hline $\begin{array}{l}\text { Test Case } \\
\text { No. }\end{array}$ & $T[\mathrm{~s}]$ & $\omega[\mathrm{rad} / \mathrm{s}]$ & $\lambda[\mathrm{m}]$ & $2 S[\mathrm{~m}]$ & $\left(\frac{H}{\lambda}\right)_{\text {Linear-Theory }}$ \\
\hline 1 & 0.57 & 11.023 & 0.5 & 0.007 & 0.0177 \\
\hline 2 & 0.70 & 8.976 & 0.76 & 0.007 & 0.01033 \\
\hline 3 & 0.83 & 7.57 & 1.08 & 0.007 & $6.38 \mathrm{e}-3$ \\
\hline 4 & 0.97 & 6.477 & 1.45 & 0.047 & 0.02738 \\
\hline 5 & 1.10 & 5.712 & 1.84 & 0.047 & 0.0185 \\
\hline 6 & 1.23 & 5.108 & 2.25 & 0.047 & 0.0129 \\
\hline 7 & 1.37 & 4.586 & 2.65 & 0.087 & 0.01756 \\
\hline 8 & 1.50 & 4.1887 & 3.06 & 0.127 & 0.0198 \\
\hline
\end{tabular}

\section{Governing equations}

The wave propagation problem in the frequency range of the present work and wave height in the intermediate depth is generally laminar and the turbulence effect can be of importance only in the vicinity of the wedge. Therefore the maximum Re No. related to the maximum velocity of the wedge with both characteristic lengths of $b$ and also 2S was calculated and compared with the critical Re. No. of a flat plate. It was seen that all Re. numbers are less than the critical value. Therefore the flow field around the wedge is assumed to be laminar.

Since the flow is assumed to be incompressible laminar flow, the continuity and momentum equations are as follows:

$\vec{\nabla} \cdot \vec{V}=0.0$

$\left.\frac{\partial \vec{V}}{\partial t}+\overrightarrow{(V} \cdot \vec{\nabla}\right) \vec{V}=-\frac{1}{\rho} \nabla p+\frac{1}{\rho} \vec{\nabla} \cdot(2 \mu \bar{D})+\vec{g}$

where $\bar{D}$ is the stress tensor rate with components: 
$D_{i j}=\frac{1}{2}\left(\frac{\partial V_{i}}{\partial X_{j}}+\frac{\partial V_{j}}{\partial X_{i}}\right)$

and $p, \mu, \vec{V}, \rho$ are the pressure, the dynamic viscosity, the fluid velocity vector and, the fluid density respectively.

Note that the dynamic condition, i.e., continuity of pressure at the interface is automatically implemented by the VOF method. The kinematic condition, which states that the interface is convected with the fluid, can be expressed in terms of the volume fraction $\varphi$ as follows [17]:

$\left.\frac{D \varphi}{D t}=\partial_{t} \varphi+\overrightarrow{(V} \cdot \vec{\nabla}\right) \varphi=0.0$

In the VOF method, the interface is described implicitly, and the data structure that represents the interface is the fraction $\varphi$ of each cell that is filled with a reference phase, say phase 1 . The scalar field $\varphi$ is often referred to as the color function. The magnitude of $\varphi$ in the cells cut by the free surface is between 0 and $1(0<\varphi<1)$ and away from it is either zero or one.

$\mu$ and $\rho$ in any cell (denoted by subscript $i j$ ) can be computed using $\varphi$ by taking a simple volume average over the cell

$\rho_{i j}=\varphi_{i j} \rho_{L}+\left(1-\varphi_{i j}\right) \rho_{a}$

$\mu_{i j}=\varphi_{i j} \mu_{L}+\left(1-\varphi_{i j}\right) \mu_{a}$

where subscripts (L) and (a) denote liquid and air respectively.

Also, equations (7) and (8) define the motion of the wave-maker mentioned above [3]:

$Y(t)=S \sin \omega t$

$V(t)=S \omega \cos \omega t$

$\omega^{2}=g k \tanh k h$

In Equations (7) and (8) the terms $Y, V$ and $S$ represent the vertical displacement, velocity and stroke amplitude of the wave-maker, respectively. The radian frequency of oscillation is $\omega$ and Equation (9) is the linear dispersion relation relating the frequency and the wave number $k=2 \pi / \lambda$.

\section{Computational schemes}

In the present study, a finite volume, ANSYS-FLUENT, code is used to solve the Navier-Stokes equations for the simulation of the flow field around the moving wedge and in the flume. A secondorder upwind scheme is used to discretize the convective terms in the momentum equations, and the SIMPLE algorithm is used for coupling the pressure and velocity based equations. Also, an explicit VOF scheme is used to capture the interface in two phase flow. A dynamic mesh scheme is used for 
the moving region. The UDF program is used to control the wave-maker velocity and stroke using Equations 7 and 8. For damping the waves, a numerical beach is applied over the last 8 meters of the flume.

\section{4-1. Mesh generation and grid independence}

We first consider the case where there is no gap between the wedge and the wall of the tank, as shown in Figure 2. A layering and sliding mesh scheme for the moving part is used. A close-up of the mesh near the wedge with the layering scheme is shown in Figure 3. This entire mesh system moves with the wedge.

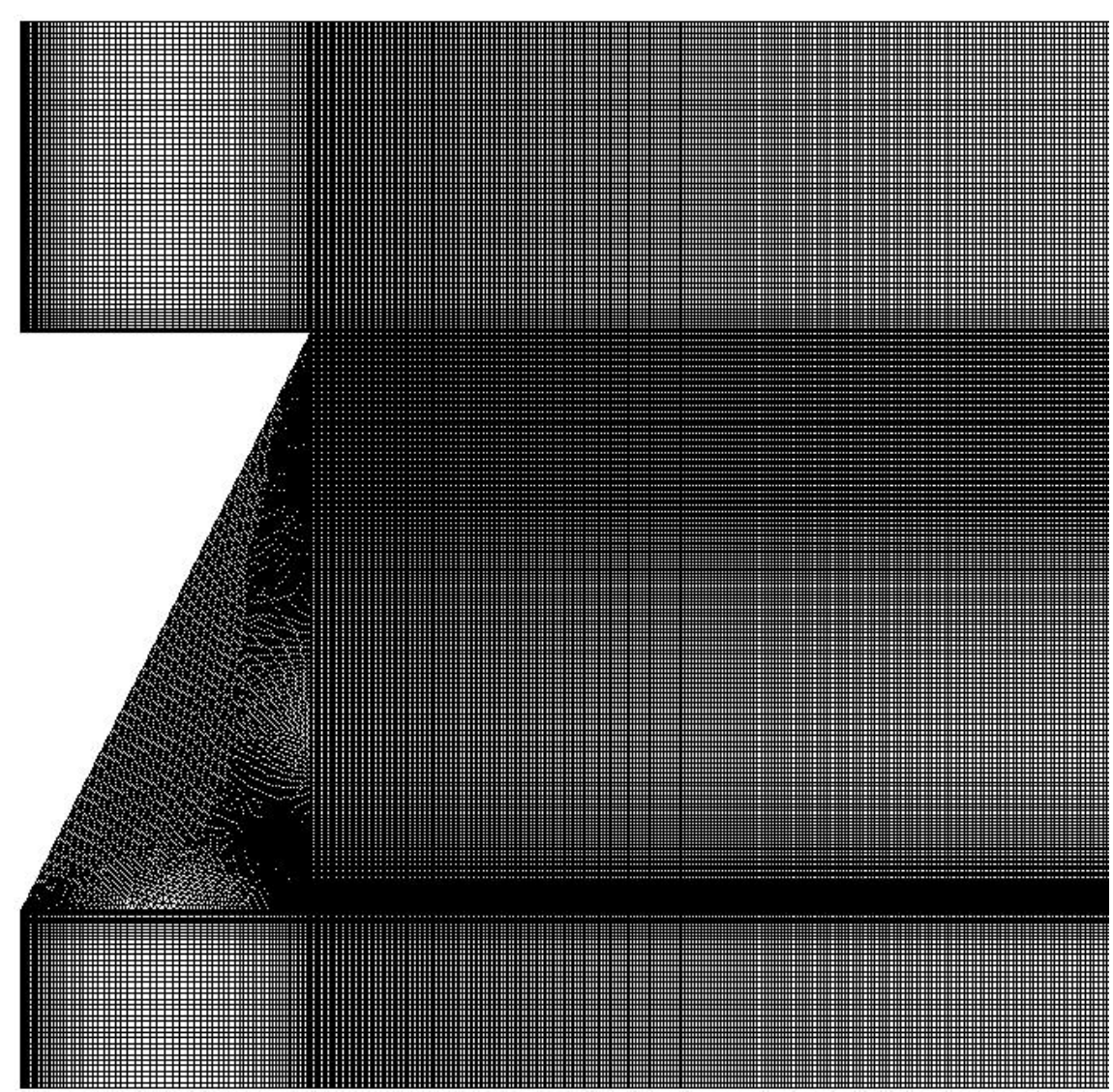

Figure 2: The wedge with no gap 


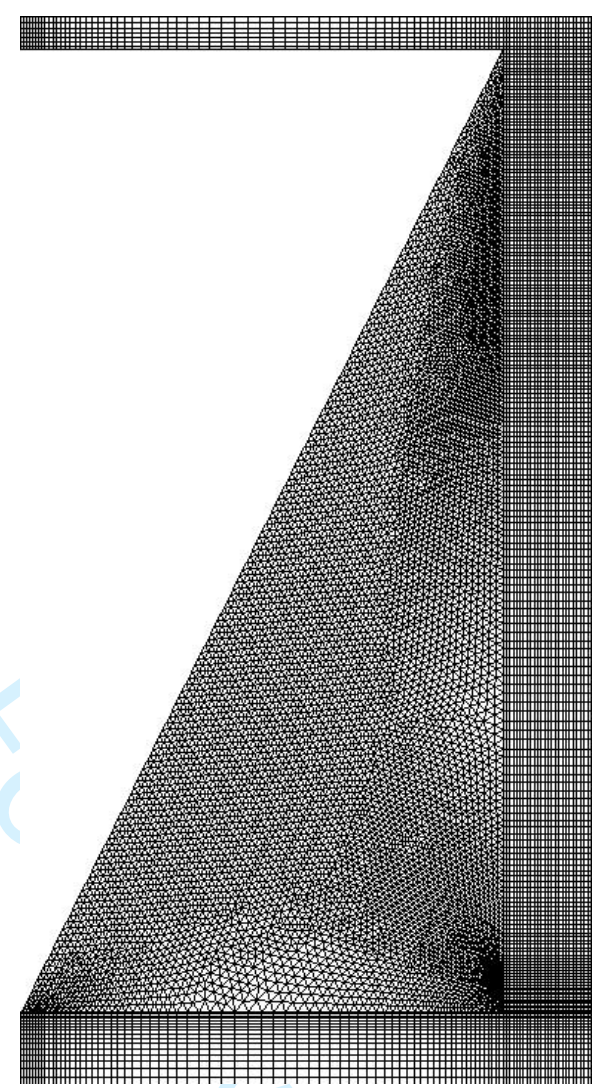

Figure 3: Close-up of the layered sliding mesh region

Having found a suitable mesh system, we first confirm the mesh independence of the calculations for test case 1 in a real installation with a $1 \mathrm{~cm}$ gap, to find the number of nodes which are sufficient to get a good result for each wave number or frequency. The $A / S$ ratio ( $A$ is the wave amplitude and $S$ is the half stoke) for the generated wave is calculated as the average of the 3 first wavelengths starting from a distance of $x=2 h$ from the wedge where the evanescent mode effects are negligible. The results are shown in Table 3 for different grid resolutions. It shows that there are no significant changes in the $A / S$ ratio for different resolutions. Therefore we conclude that at least 100 grid points per wavelength and 5 grid points per wave-height is a good mesh resolution for all calculations. Figure 4 shows the wave elevation versus position for test case 7 with 100 nodes and 200 nodes per wavelength and the results of the two calculations agree very well. 
Table 3: Grid independency check

\begin{tabular}{|l|l|l|l|l|}
\hline Case No. & $\begin{array}{l}\text { Nodes per } \\
\text { wavelength }\end{array}$ & $\begin{array}{l}\text { Nodes per Wave- } \\
\text { Height }\end{array}$ & Amplitude Ratio & Percent Difference \\
\hline 1 & 100 & 5 & 1.257 & \\
\hline 1 & 150 & 5 & 1.258 & 0.08 \\
\hline 1 & 100 & 11 & 1.26 & 0.23 \\
\hline
\end{tabular}

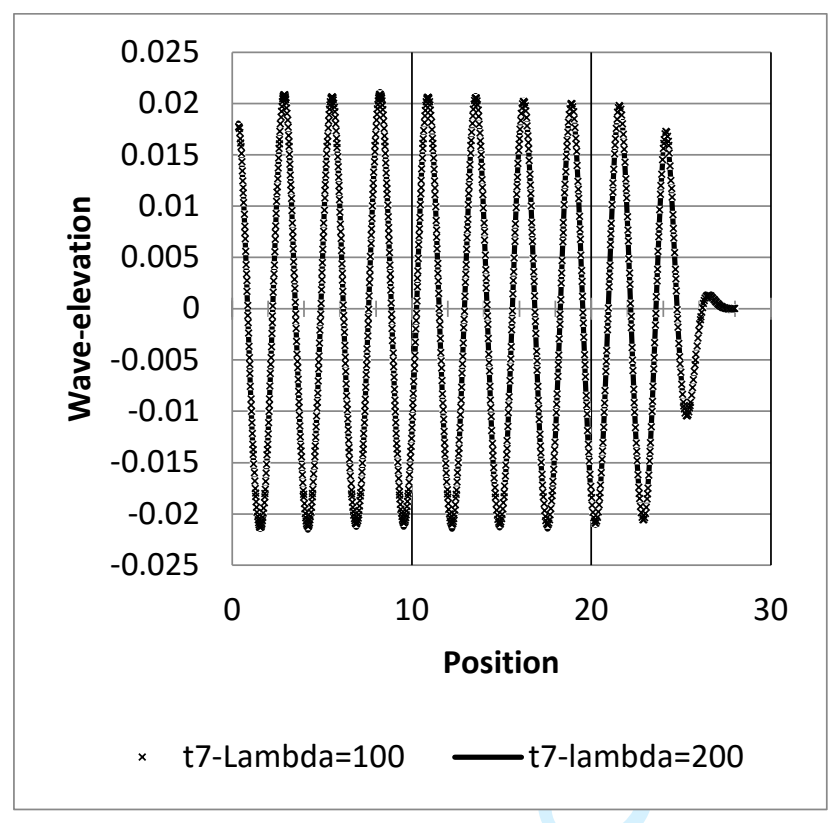

Figure 4 : Grid independency in angular frequency of 4.587

\section{Comparison with linear potential flow theory with no gap}

For validating the method and schemes, the present results with no gap are compared to the linear potential flow solutions using the semi-analytic method of $\mathrm{Wu}$ [3] and also by numerical solution using the OceanWave3D (OW3D) finite difference method solver [18]. The average $A / S$ ratio for the three solutions is plotted versus wave angular frequency in Figure 5 and tabulated in Table 4. The present $A / S$ ratios show a maximum difference of $4 \%$ compared to linear theory, therefore the results are in a good agreement with this theory. The theoretical wave elevation versus position in test case 5 is compared with the present calculations in Figure 6, also showing a very good agreement. 
Table 4: Comparison of amplitude ratio in present work with Wu theory

\begin{tabular}{|c|c|c|c|c|c|c|c|}
\hline Case & $\mathrm{T}(\mathrm{s})$ & $\lambda(\mathrm{m})$ & $\begin{array}{c}\text { Steepness } \\
\mathrm{Wu} \\
\text { No. }\end{array}$ & $\begin{array}{c}\text { Steepness } \\
\text { Present } \\
\text { theory }\end{array}$ & $\begin{array}{c}\text { Amplitude } \\
\text { Ratio } \\
\text { Wu theory }\end{array}$ & $\begin{array}{c}\text { Amplitude } \\
\text { Ratio } \\
\text { Present } \\
\text { work }\end{array}$ & $\begin{array}{c}\text { \% difference } \\
\text { in Amplitude } \\
\text { Ratio }\end{array}$ \\
\hline 1 & 0.57 & 0.5 & 0.0177 & 0.01714 & 1.265 & 1.267 & 0.16 \\
\hline 2 & 0.7 & 0.76 & 0.1033 & 0.01039 & 1.122 & 1.1492 & 2.42 \\
\hline 3 & 0.83 & 1.08 & $6.38 \mathrm{e}-3$ & 0.00614 & 0.985 & 0.944 & 4.16 \\
\hline 4 & 0.97 & 1.45 & 0.02738 & 0.266 & 0.845 & 0.839 & 0.71 \\
\hline 5 & 1.10 & 1.84 & 0.0185 & 0.0183 & 0.724 & 0.727 & 0.41 \\
\hline 6 & 1.23 & 2.25 & 0.0129 & 0.01286 & 0.6217 & 0.6215 & .032 \\
\hline 7 & 1.37 & 2.65 & 0.01756 & 0.01665 & 0.535 & 0.5294 & 1.046 \\
\hline 8 & 1.50 & 3.06 & 0.0198 & 0.01924 & 0.47688 & 0.4672 & 2.02 \\
\hline
\end{tabular}

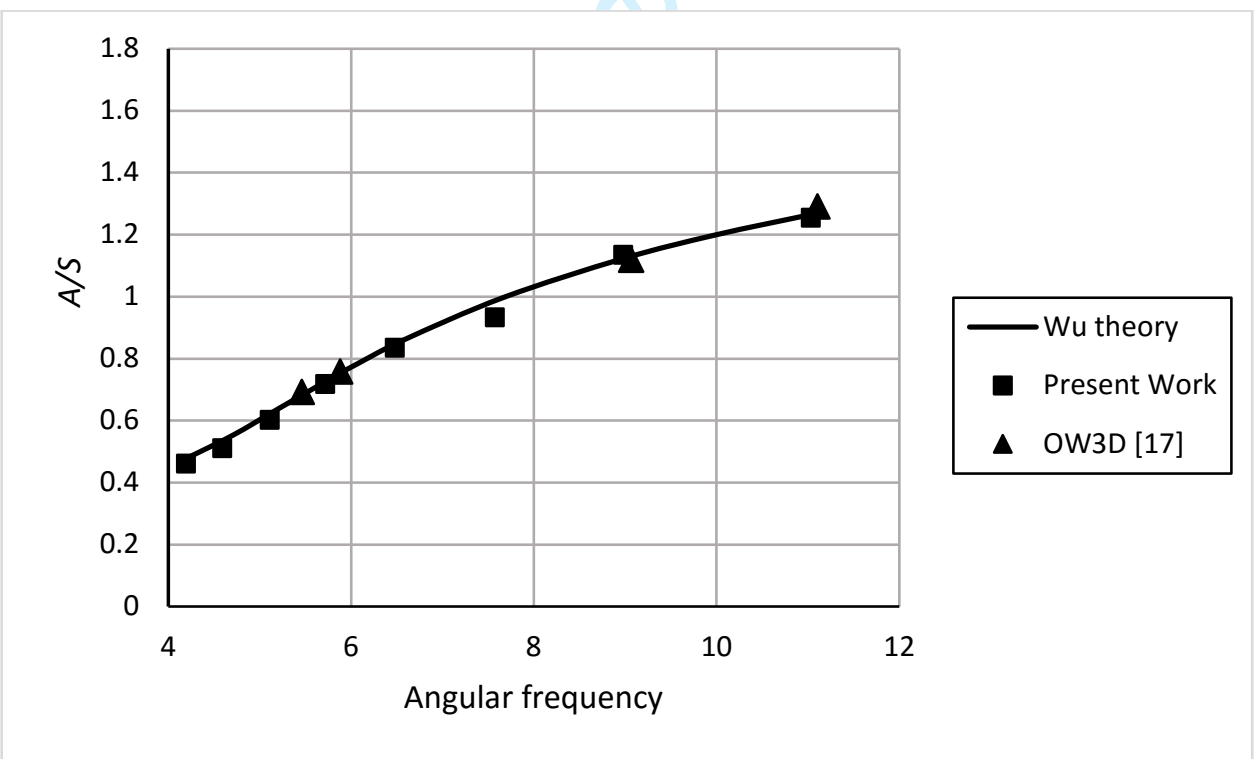

Figure 5: Comparison of wave amplitude to stroke amplitude ratio in the present work with linear theory of Wu [3] and OW3D [18]. 


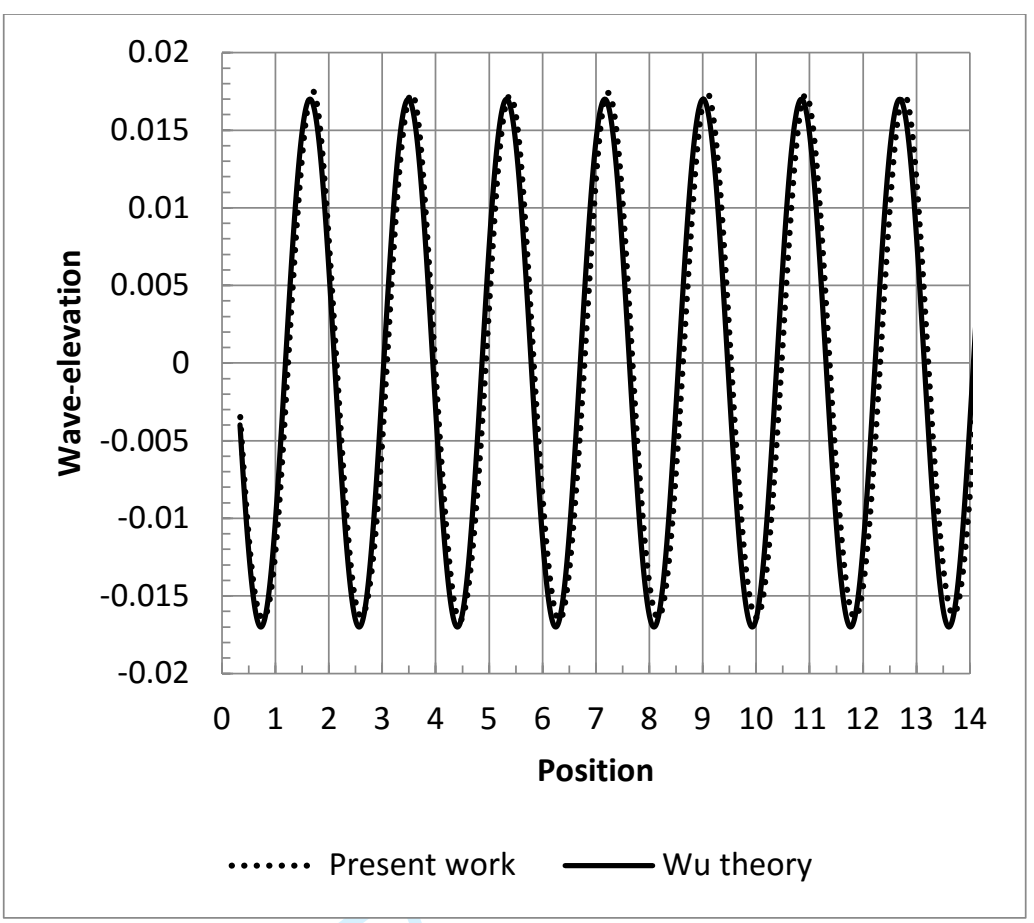

Figure 6: Comparison of theoritical wave elevation with the present work for wave angular frequency of 5.712

\section{Effect of the gap behind the wedge:}

It is of importance to know the effect of the gap between the flume wall and the back of the wedge. Therefore, the $1 \mathrm{~cm}$ gap in the back of the wedge is divided into 3, 6 and 20 parts to check the grid independency in this region. Changing the resolution of the mesh shows no effect on the wave elevation. Table 5 shows the comparison of the $A / S$ ratio of the wedge with gap and without gap in all test cases and it shows that the maximum difference in the $A / S$ ratio is about $3 \%$. Figure 7 also includes experimental results from [18]. These experimental results were obtained in a narrow flume with width $0.6 \mathrm{~m}$. Figure (7) shows that the results are in a good agreement with the experimental ones.

To understand better the flow in the gap, we consider the velocity vector of test case 6 , for the mesh with the highest resolution and with a period of $\mathrm{T}=1.23$ seconds. The region near the bottom of the wedge, at four instants of time over one period, is sketched in Figure 8 and Figure 9. Although in the bottom region of the wedge, due to the generated vortexes, the vorticity magnitude is relatively high, it does not reduce the energy of the generated wave, as the wave height is the same with and without the gap. Since both of these calculations also agree quite well with the predictions of linear potential flow theory, we can conclude that the narrow gap do not extract energy from the generated wave. 
Table 5 : Comparison of the wave amplitude ratio in the wedge with the gap and the no-gap wedge

\begin{tabular}{|c|c|c|c|c|c|}
\hline Case No. & $\mathrm{T}(\mathrm{s})$ & $\lambda(\mathrm{m})$ & $\begin{array}{c}\text { Wave amplitude } \\
\text { Ratio } \\
\text { of } 1 \mathrm{~cm} \text { gap wedge }\end{array}$ & $\begin{array}{c}\text { Wave amplitude } \\
\text { Ratio } \\
\text { Of no-gap wedge }\end{array}$ & $\begin{array}{c}\text { Percent of } \\
\text { wave-height } \\
\text { increase }\end{array}$ \\
\hline 1 & 0.57 & 0.5 & 1.255 & 1.267 & 0.956 \\
\hline 2 & 0.7 & 0.76 & 1.1354 & 1.1492 & 1.215 \\
\hline 3 & 0.83 & 1.08 & 0.9344 & 0.944 & 1.027 \\
\hline 4 & 0.97 & 1.45 & 0.836 & 0.839 & 0.36 \\
\hline 5 & 1.10 & 1.84 & 0.719 & 0.727 & 1.112 \\
\hline 6 & 1.23 & 2.25 & 0.6114 & 0.6215 & 1.652 \\
\hline 7 & 1.37 & 2.65 & 0.5111 & 0.5294 & 3.6 \\
\hline 8 & 1.50 & 3.06 & 0.462 & 0.4672 & 1.126 \\
\hline
\end{tabular}

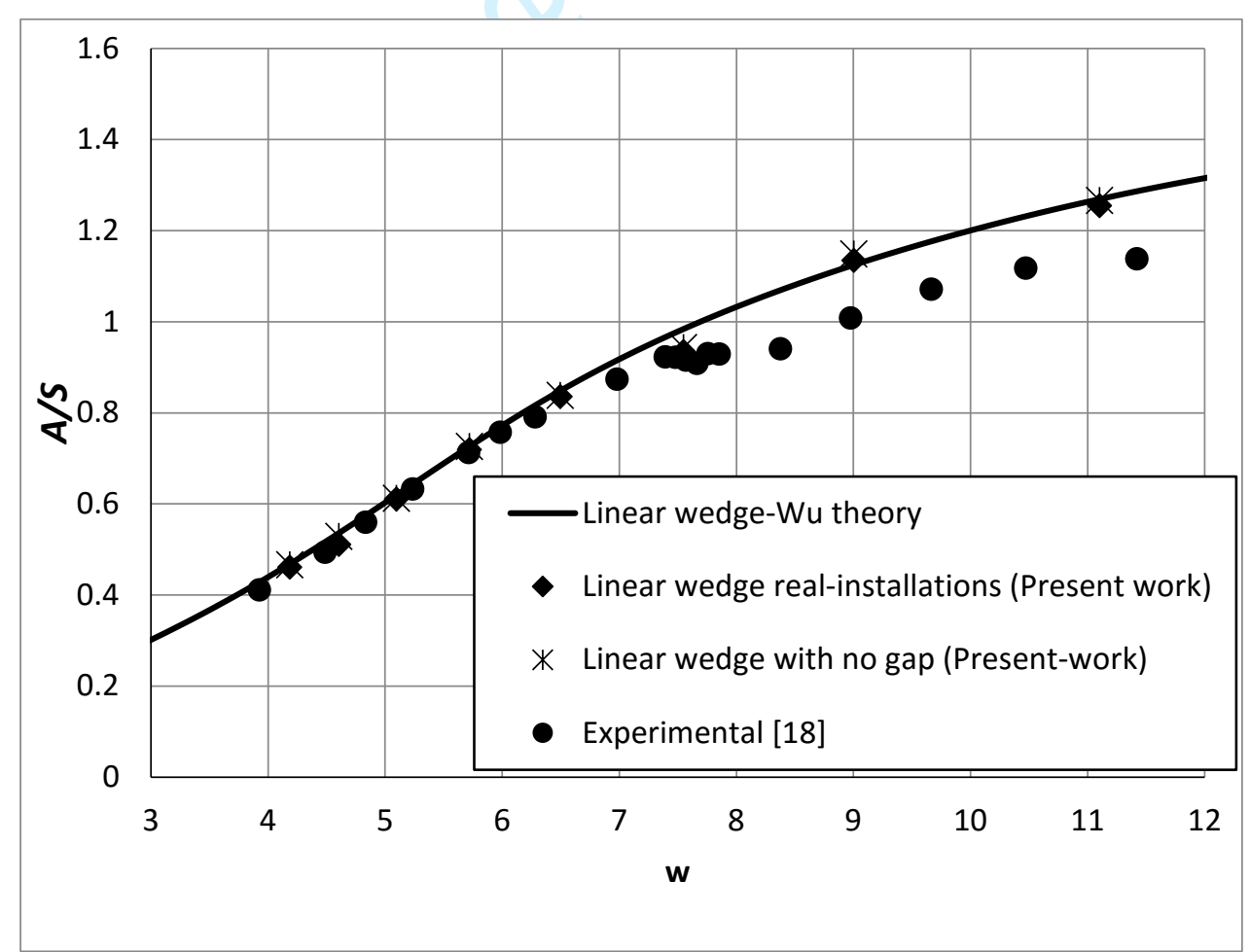

Figure 7: Comparison of wave to stroke amplitude ratio in the present work with a $1 \mathrm{~cm}$ gap (real-instalations), no gap behind the wedge with linear theory of $\mathrm{Wu}$ [3] and experiments [18] 


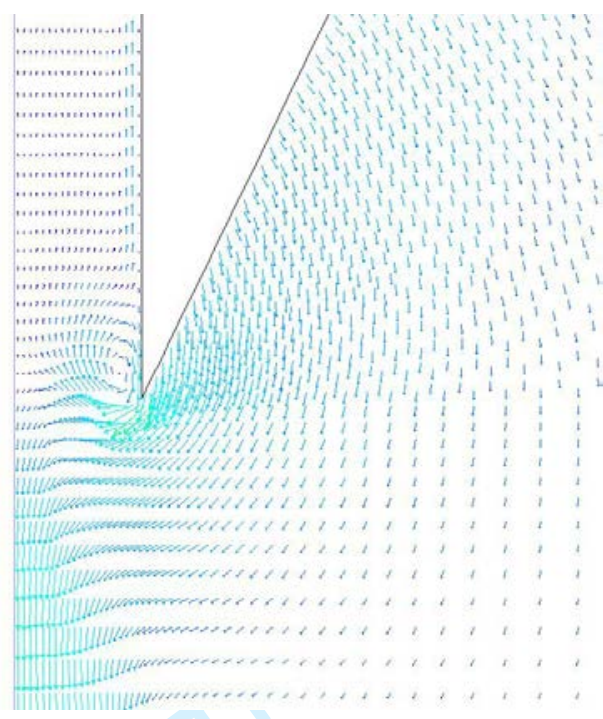

(a): $T / 4$

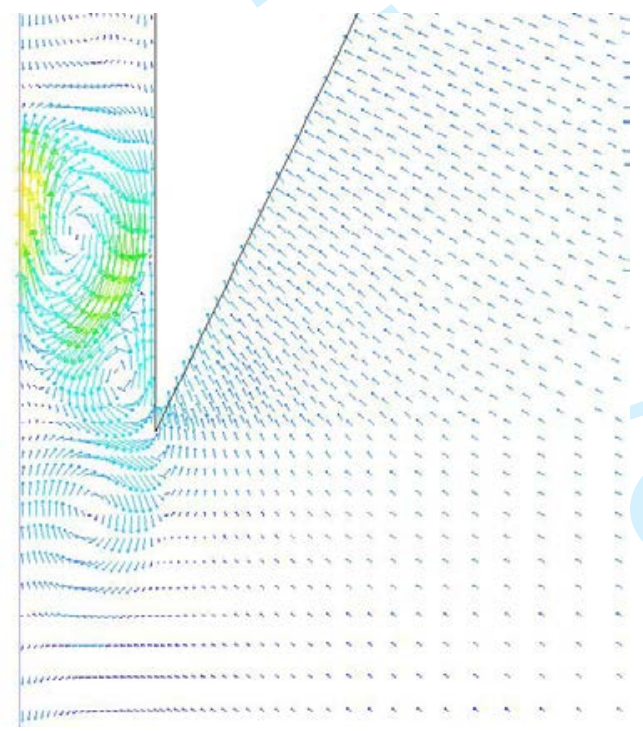

(c): $3 \mathrm{~T} / 4$

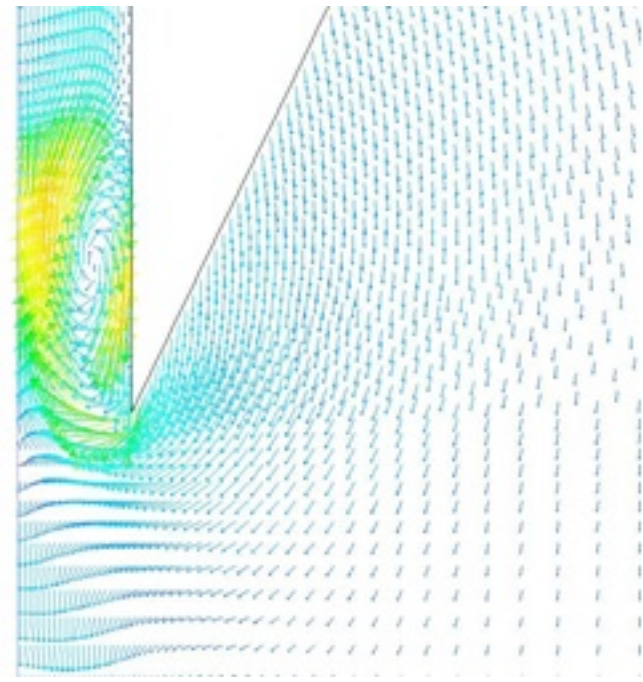

(b) $: \mathrm{T} / 2$

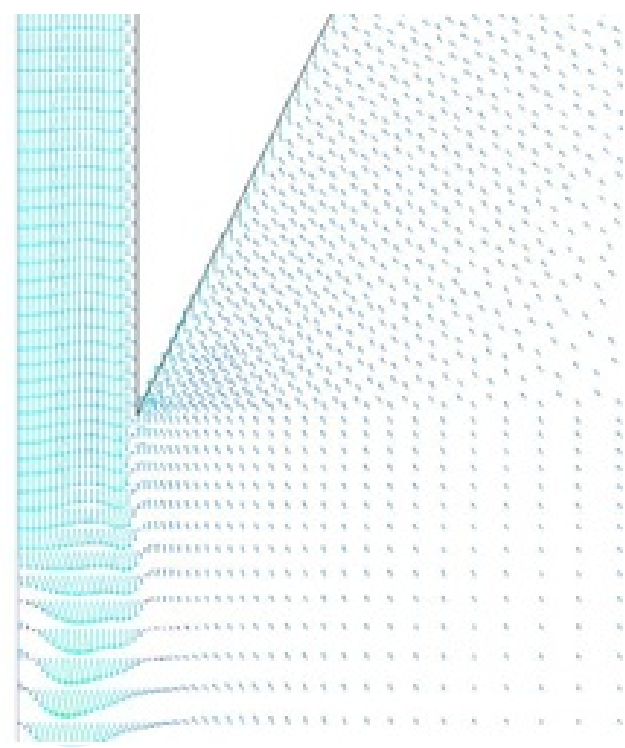

(d): T

Figure 8: Velocity vector (m/s) at four instants of time over one period after 30 seconds $(\mathrm{T}=1.23 \mathrm{sec})$ 


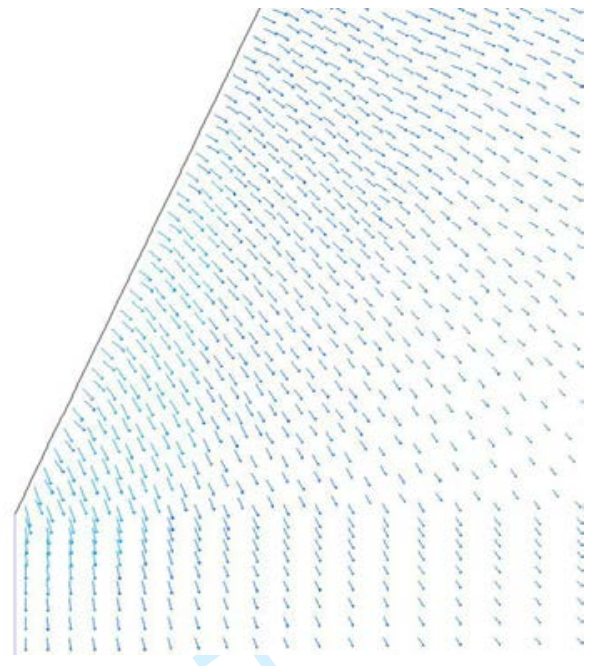

(a): $T / 4$

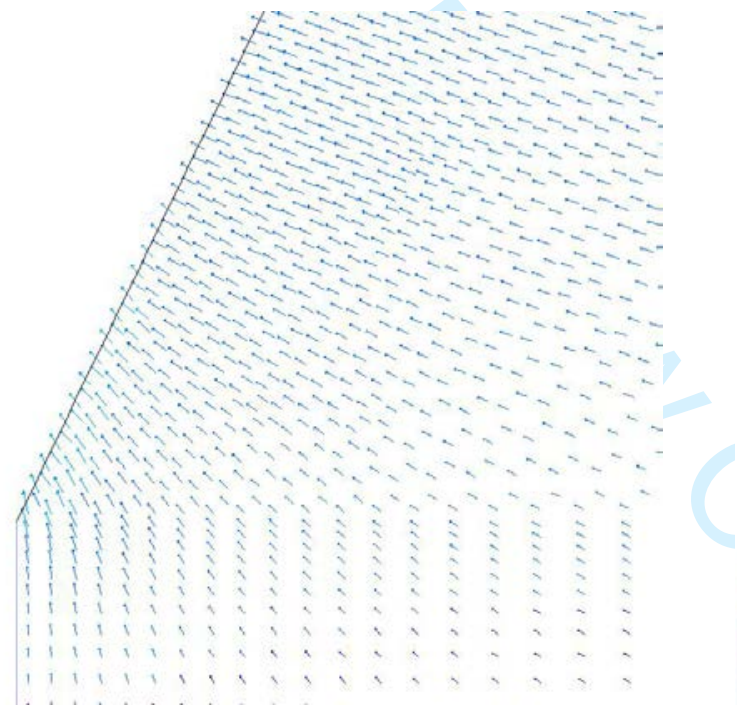

(c): $3 \mathrm{~T} / 4$

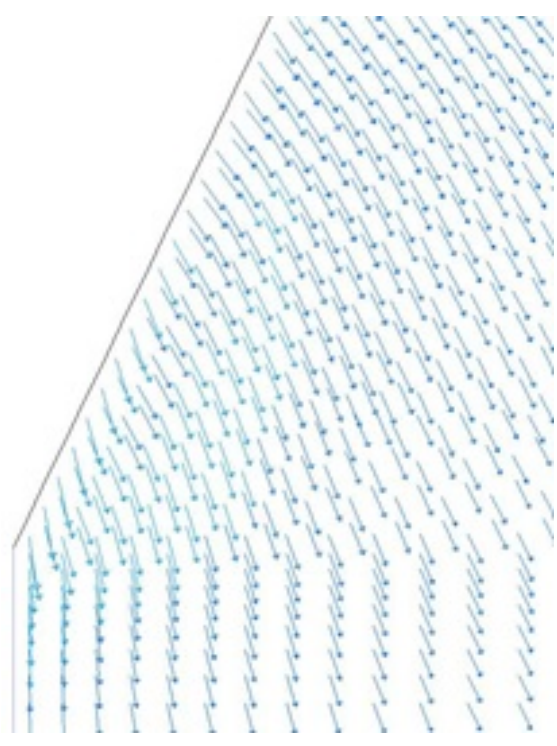

(b) $: T / 2$

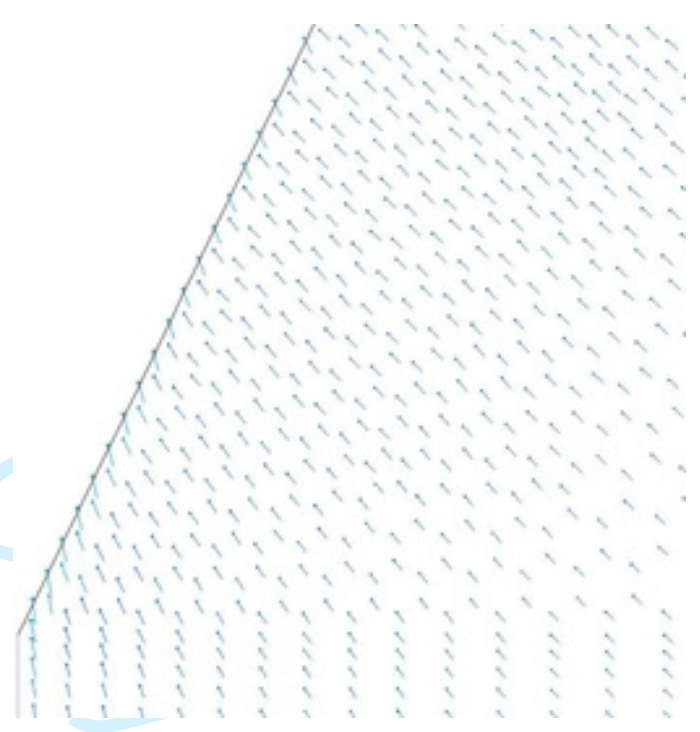

(d): $\mathrm{T}$

Figure 9: Velocity vector $(\mathrm{m} / \mathrm{s})$ at four instants of time over one period after 30 seconds for the no-gap wedge $(\mathrm{T}=1.23$ sec)

We now consider the effect of increasing the size of the gap between the wedge and the wall to 50 $\mathrm{cm}$. Figure 10 shows the vorticity in front of the wave maker for test case 2 (high angular frequency) and test case 6 (moderate angular frequency). The difference between the generated wave heights with and without a large gap is approximately 3.5 percent in test case 2 and 12.5 percent in test case 8 . Clearly a large gap allows for some leakage of wave energy behind the 
wedge, and this leakage increases with increasing wave length. For high-frequency wedge motions, the generated wave behind the wedge has a very small amplitude. However, for longer waves (lower frequency) the wave behind the wedge becomes more significant and has a larger effect on the generated wave.

Figure 11 shows an envelope plot of the surface elevation both behind and in front of the wedge for test case 4. From this, we can see that significant motion is induced in the gap which appears to consist mostly of a piston mode at the forcing frequency, together with the first sloshing mode in the gap. This leads to significant irregularity in the wave generated in front of the wedge, which is also depicted in Figure 12. This shows the importance of keeping the gap behind the wedge as small as possible. 


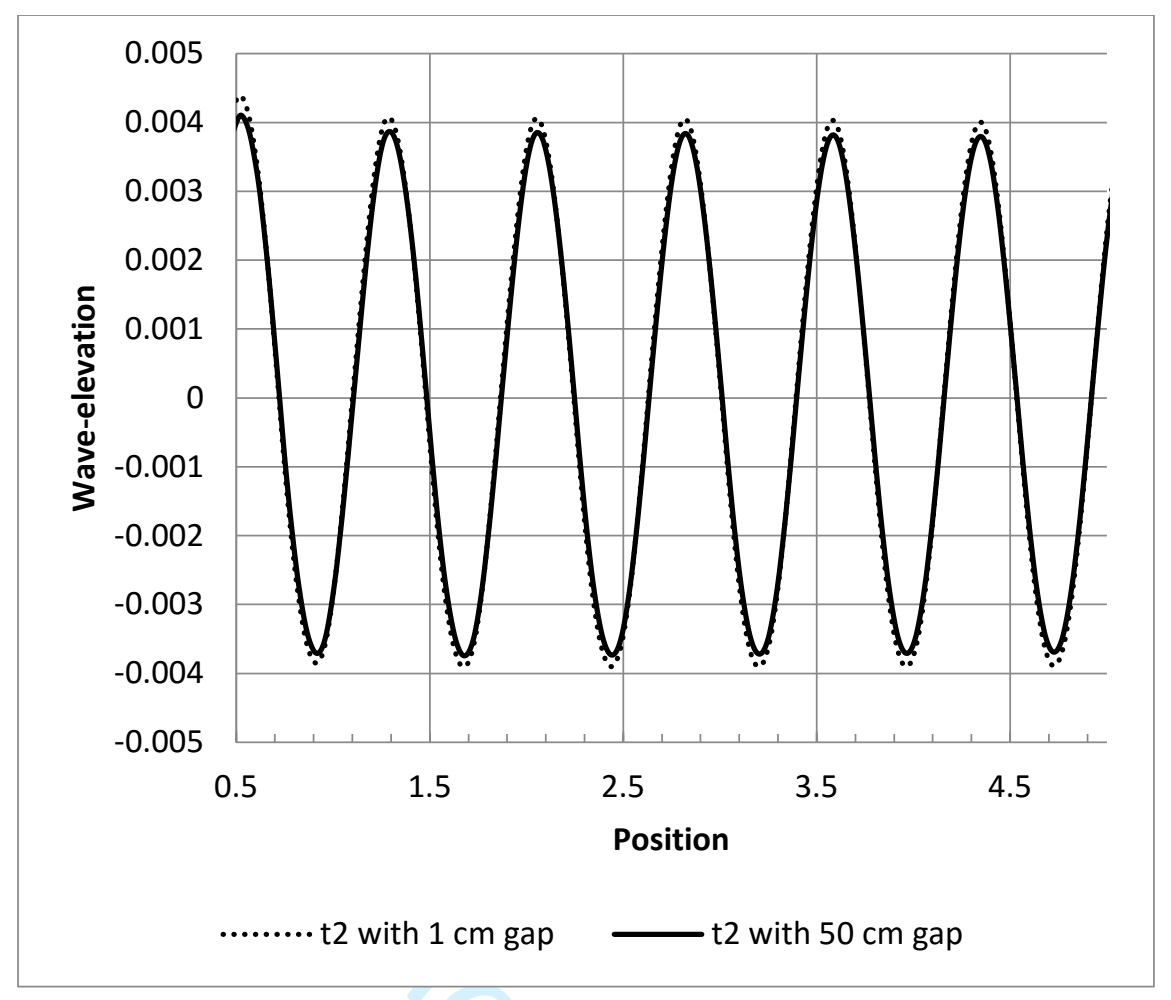

(a) with angular frequency of 8.976

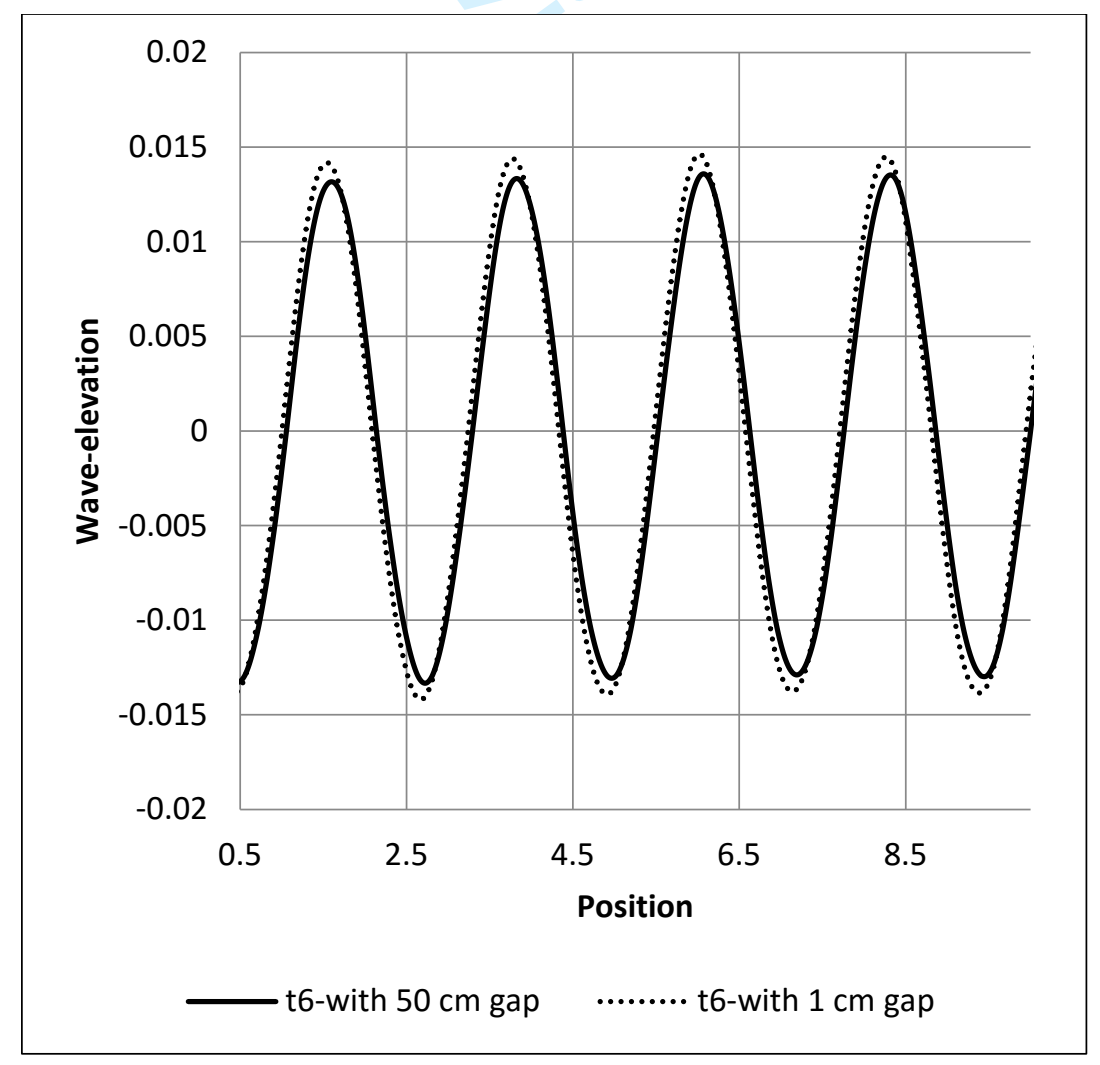

(b) with angular frequency of 5.108

Figure 10: Comparison of wave height with different gaps behind the wedge 


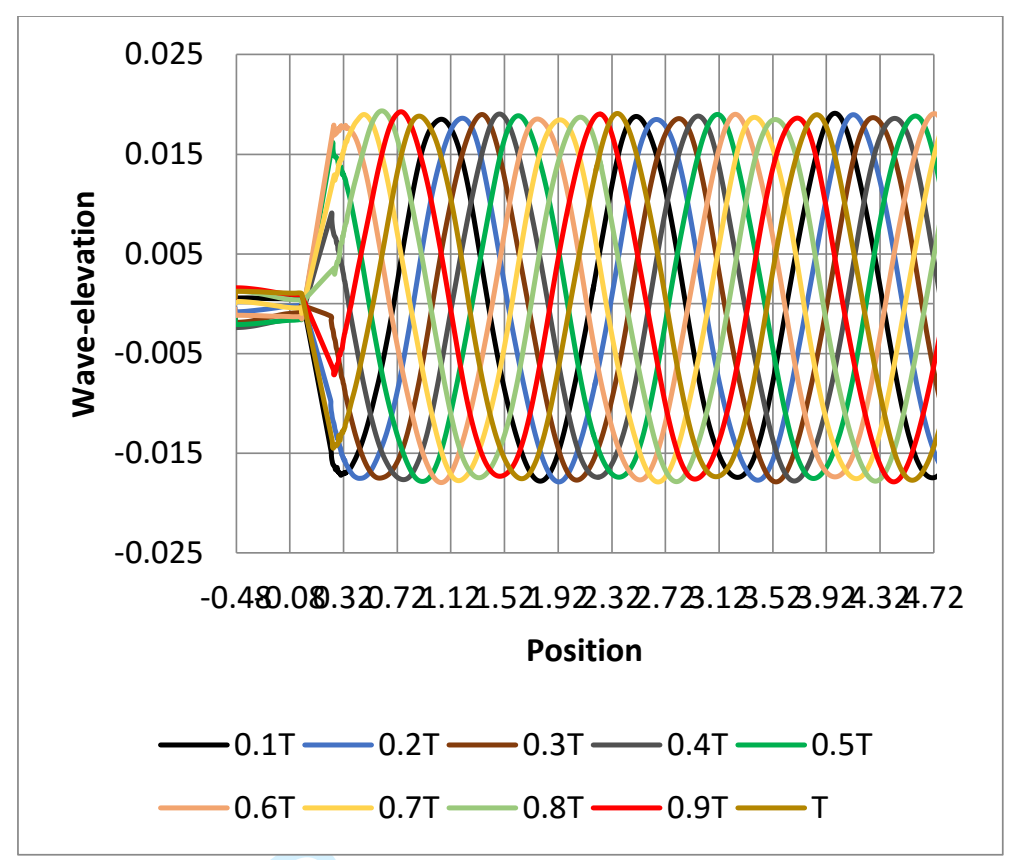

Figure 11: an envelope plot of the surface elevation both behind and in front of the wedge for test case 4

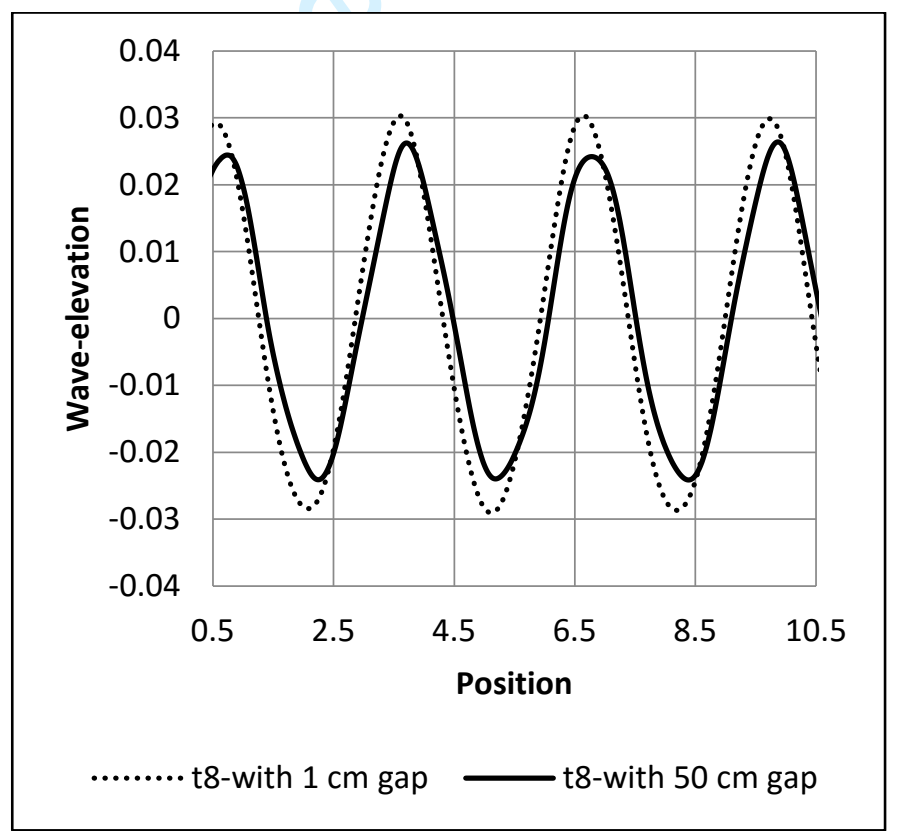

Figure 12: Comparison of wave height with different gaps behind the wedge for angular frequency of 4.188

\section{The effect of wedge shape}

In this section, the effect of wedge shape in generating the wave is investigated. Three different 2D geometries as possible shapes for the floating body are shown in Figure 13. 


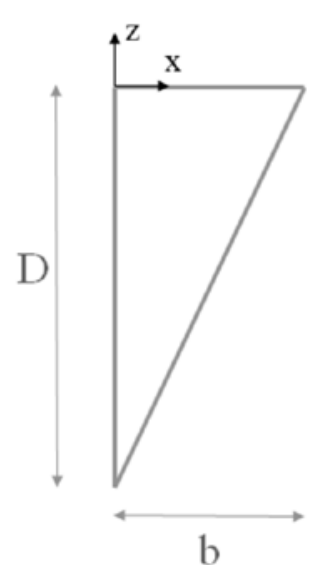

a: Triangular wedge

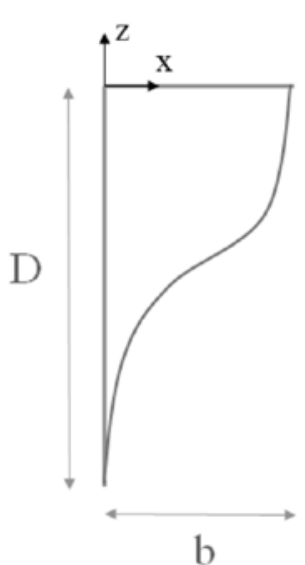

b: Berkeley wedge

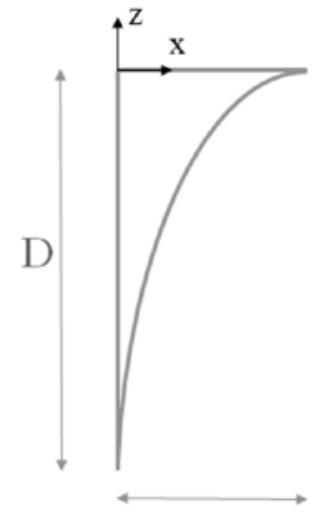

b

c: Hyperbolic-sine curve wedge

Figure 13: Three different wedge shapes for wave generating

In all wedges, the initial submerged volume should be the same and also the draft of the wedge $d$ is equal to $0.45 \mathrm{~m}$, with these two conditions and the following formulas describing the Berkeley wedge [15] and the hyperbolic-sine curve wedge can be defined.

Equation (10) is the hyperbolic-sine function of the wedge:

$X(y)=\frac{b_{0} \sinh (a(y+d))}{\sinh (a d)}$

$b_{0}=\frac{\Delta a \sinh (a d)}{(\cosh (a d)-1)}$

where $\Delta$ is the initial submerged volume of the triangular wedge and $a=\frac{\pi}{d}$.

Also the formulation of the Berkeley wedge is as follows:

$X(y)=b_{B}\left(A\left(\frac{y+d}{d}\right)^{2}+B\left(\frac{y+d}{d}\right)^{3}+C\left(\frac{y+d}{d}\right)^{4}\right)$

$A=3+C, B=-2-2 C, C=\frac{\left(3+6 d_{*}\right)}{\left(6\left(d_{*}+1\right)^{2}-6 d_{*}-5\right)}$

where $b_{B}$ is the beam to give the same volume as the triangular wedge and $d_{*}=-0.335$.

The two new wedges are sketched in the gambit software and a mesh with the same resolution as the triangular wedge is generated, as shown in Figure 14 and Figure 15. 

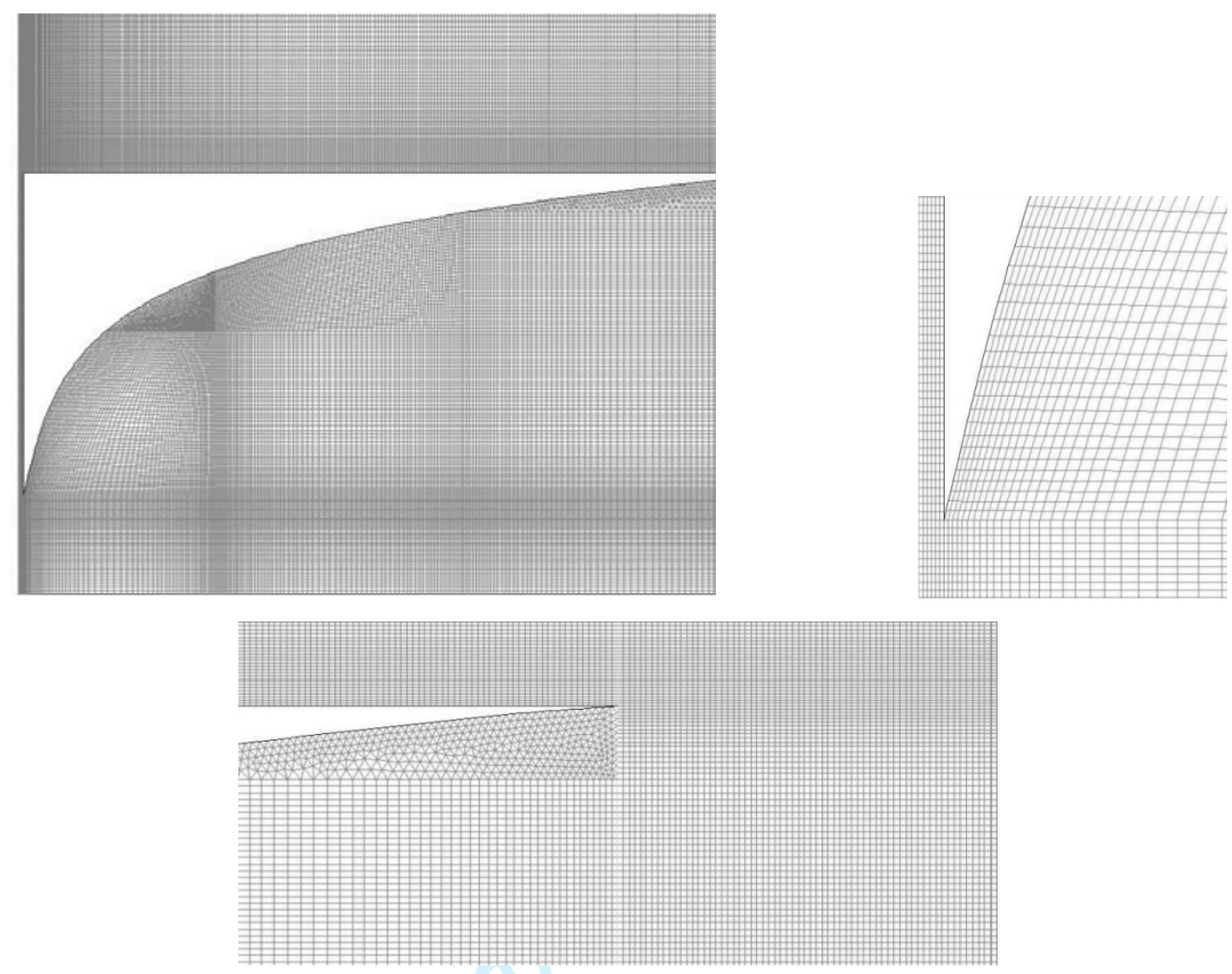

Figure 14: Generated mesh around hyperbolic-sine wedge
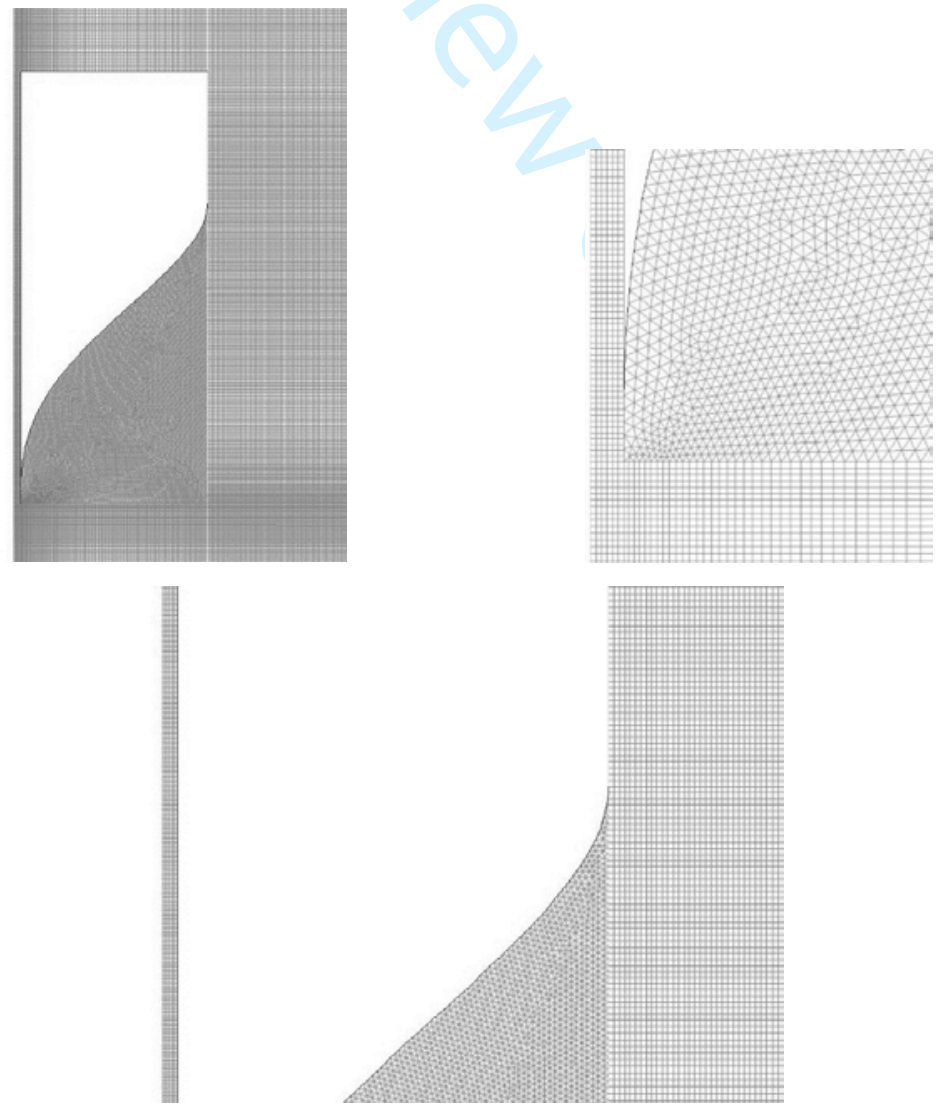

Figure 15: Generated mesh around Berkeley wedge 


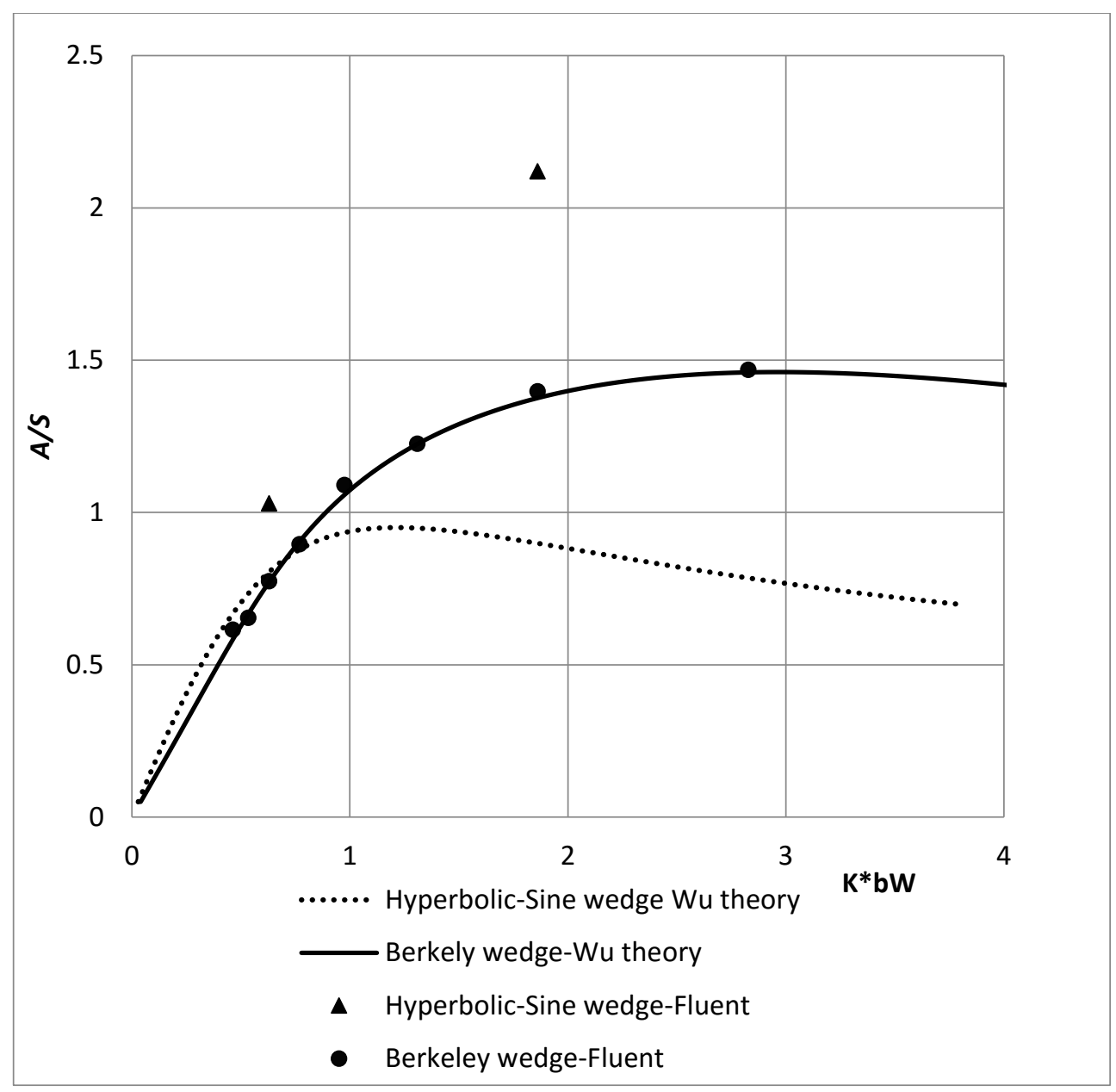

Figure 16: Comparison of Wu theory with present work for hyperbolic-sine and Berkeley wedge in test cases 2 and 6

Figure 17 and Figure 18 show the wave elevation versus position for the two wedges in test case 6. They show that in both cases some irregularity in the waves appears, but for the Berkeley wedge, the shape of the waves is better than for the hyperbolic-sine wedge. To further investigate of the flow field, the velocity vectors in both cases are shown in Figure 19 for test case 6. It can be seen that for the hyperbolic-sine shape, the velocity profile in the air region, between the free surface and 
the wedge, is very complex and some large vortices are generated with the velocity of the air near the free surface reaching nearly $6.5 \mathrm{~m} / \mathrm{s}$. This evidently has a strong effect on the shape of the wave. For the Berkeley wedge, the maximum velocity of the air is approximately $0.6 \mathrm{~m} / \mathrm{s}$ and it does not affect the free surface shape. It seems that estimating the $A / S$ ratio and finding a transfer function for the hyperbolic-sine wedge is very difficult. The very high gradient of the profile at the intersection with the free surface produced by this shape does not seem to be a good choice for such a wavemaker.

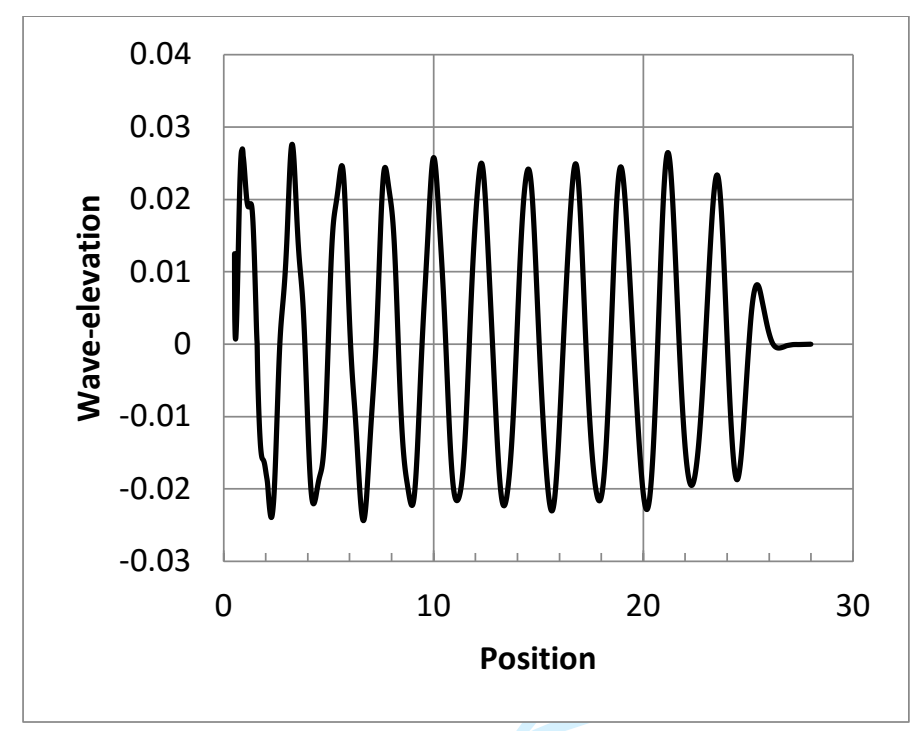

Figure 17: Wave elevation versus position for test case 6 for hyperbolic-sine wedge

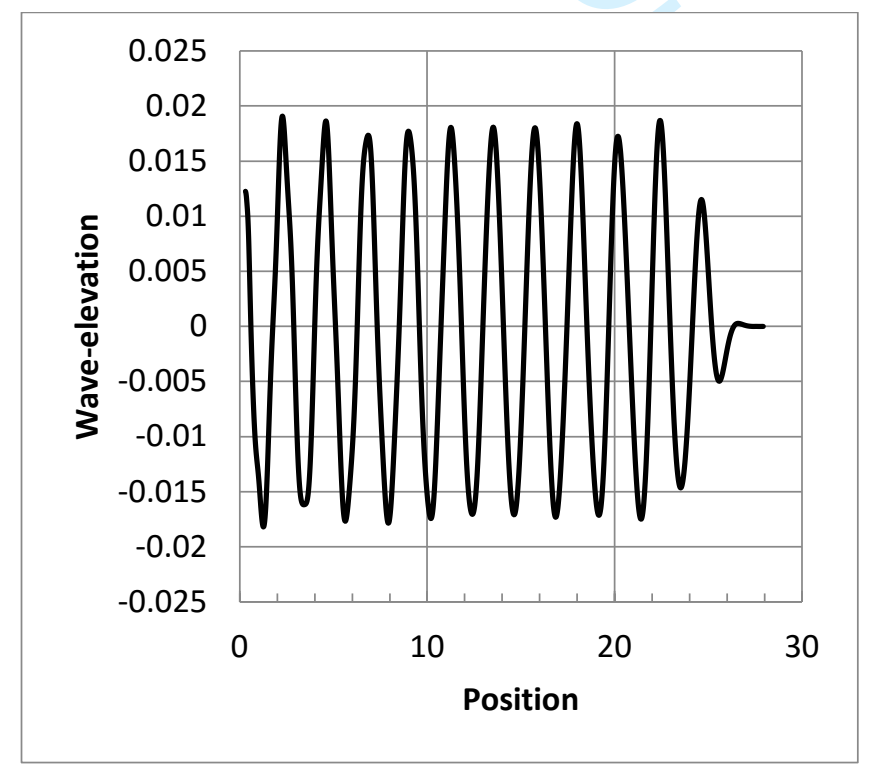

Figure 18: Wave elevation versus position for test case 6 for Berkeley wedge 


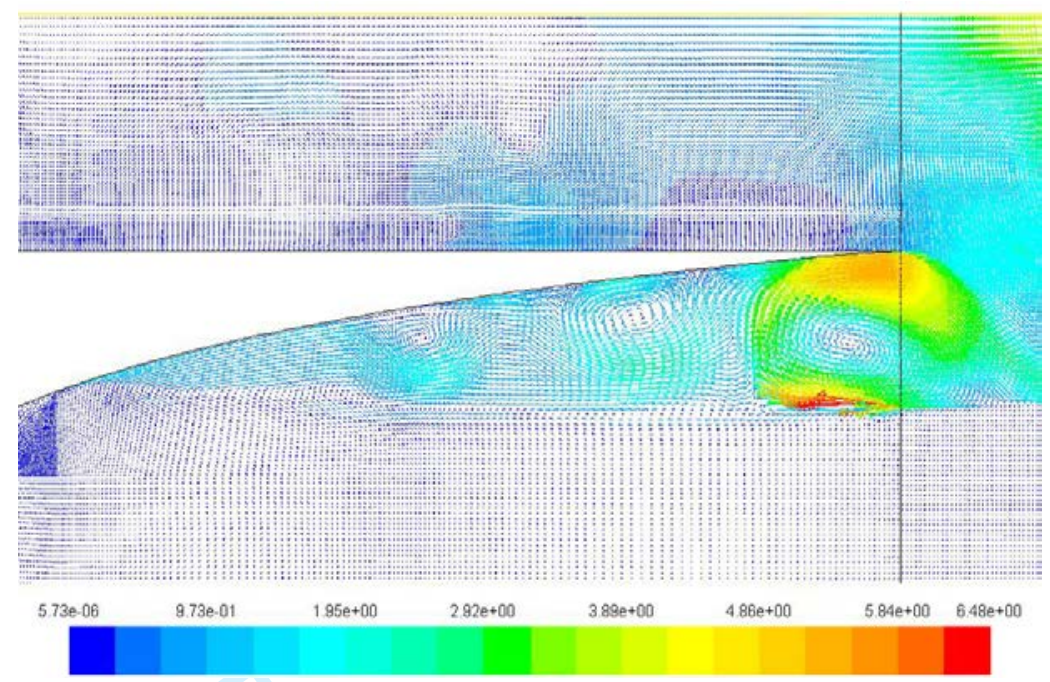

(a) Hyperbolic-sine wedge

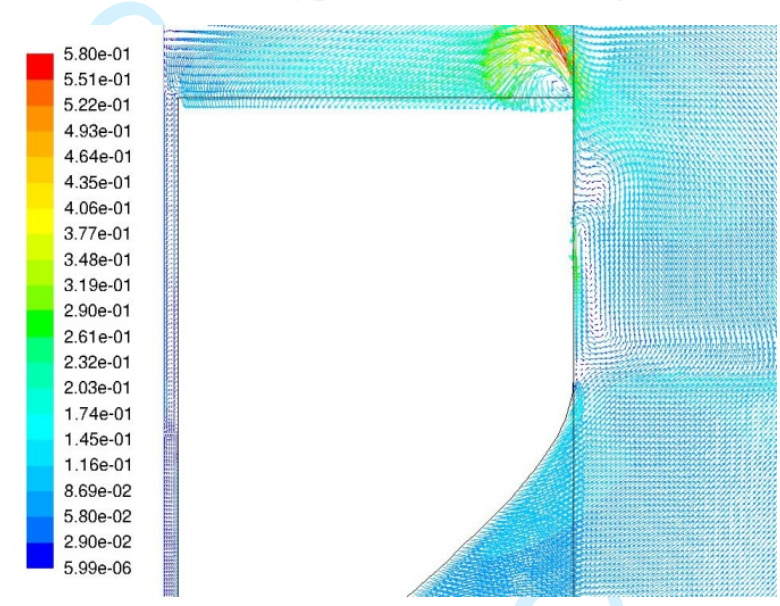

(b) Berkeley wedge

Figure 19: Velocity vector on free surface in different wedge wave-makers a) Hyperbolic-sine wedge b) Berkeley wedge

For a closer investigation of the flow field in the gap behind each wedge, the velocity vector in the bottom region of the wedges at four instants of time during one period are sketched in Figure 20 and Figure 21 for test case 6 with the time period of $\mathrm{T}=1.23$ seconds. Although the velocity profile is more complex in the bottom region of the Berkeley wedge, if these figures are compared with those of the triangular wedge, it can be observed that in both the Berkeley wedge and the hyperbolic-sine wedge similar to the triangular wedge, the flow in the gap has no effect on the wave height. 


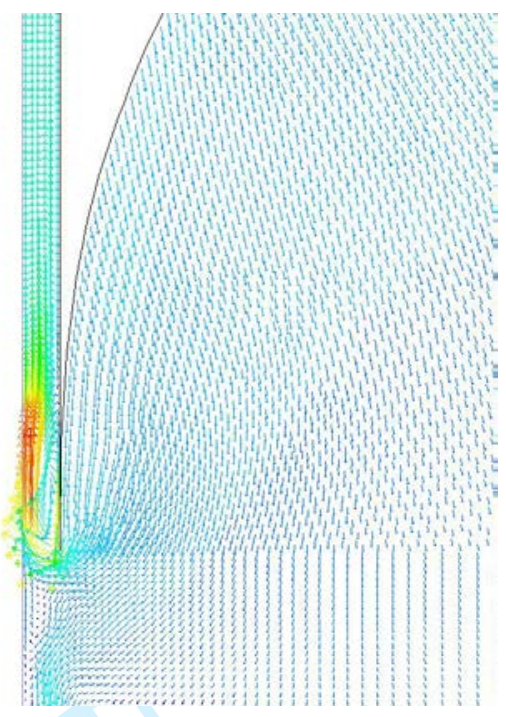

(a): $T / 4$

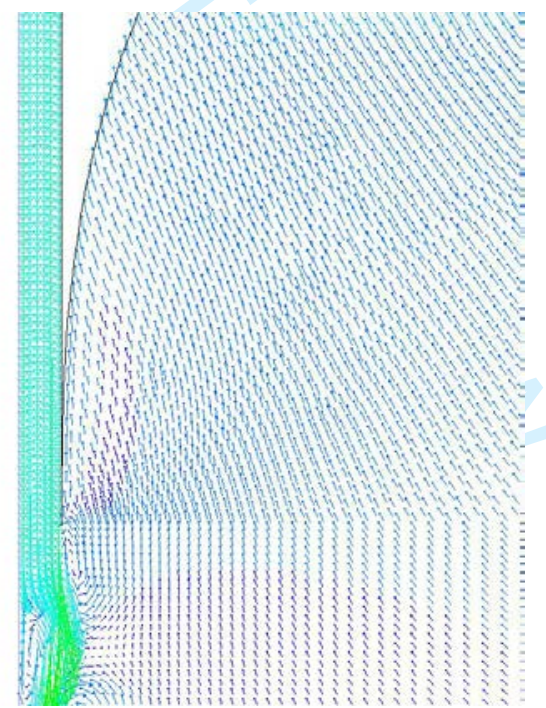

(c): 3T/4

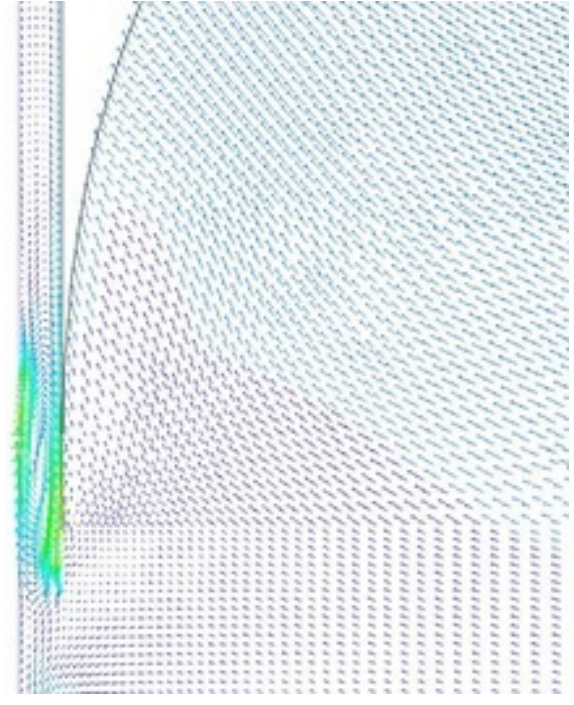

(b) : $\mathrm{T} / 2$

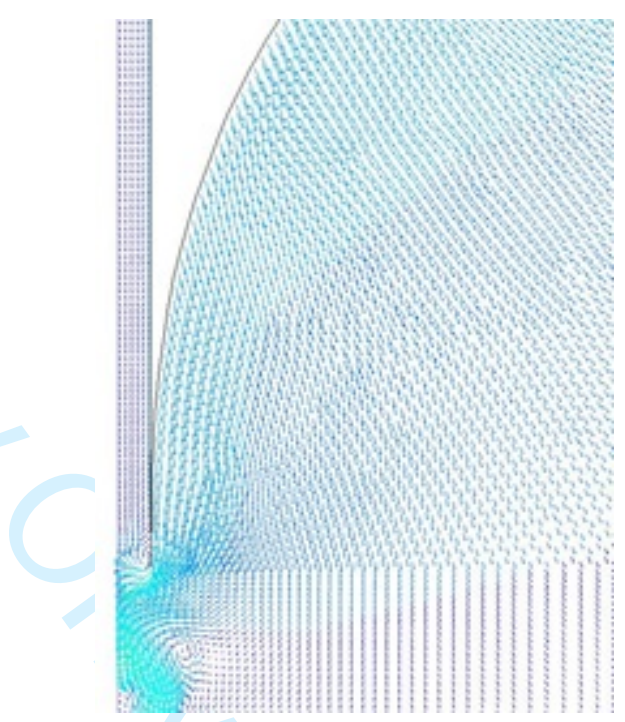

(d): $\mathrm{T}$

Figure 20: Velocity vector (m/s) at four instants of time during one period after 30 seconds for the Berkeley wedge 


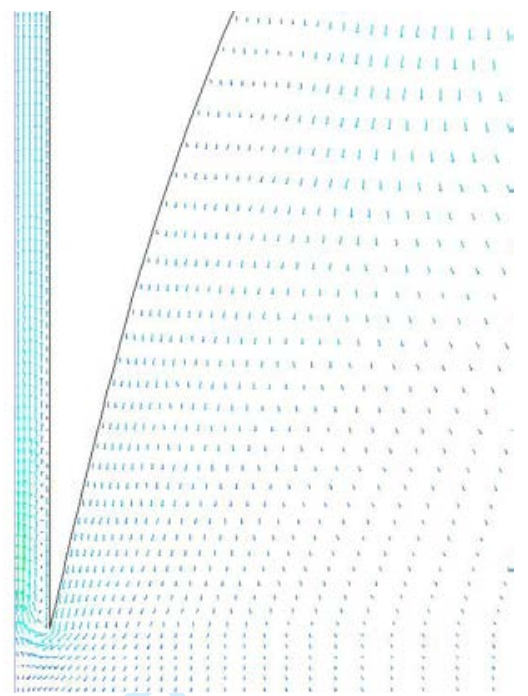

(a): $T / 4$

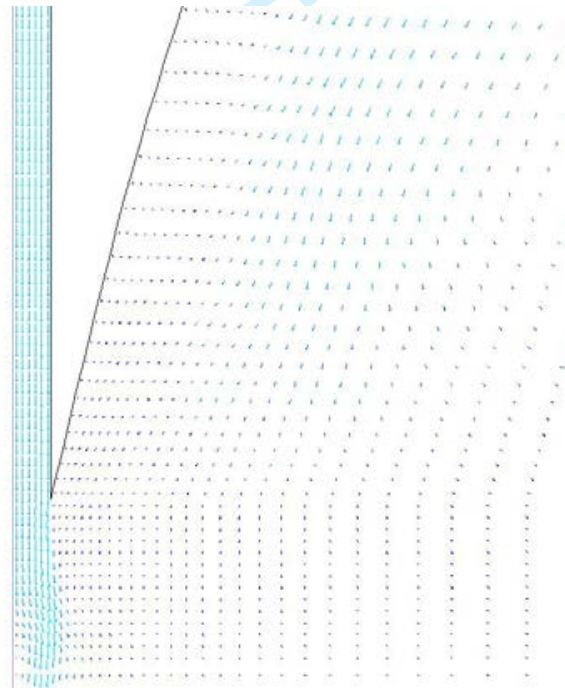

(c): $3 \mathrm{~T} / 4$

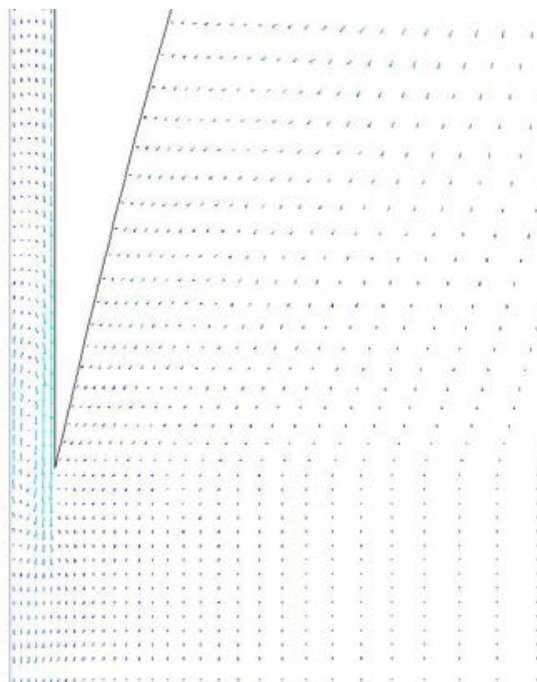

(b) $: \mathrm{T} / 2$

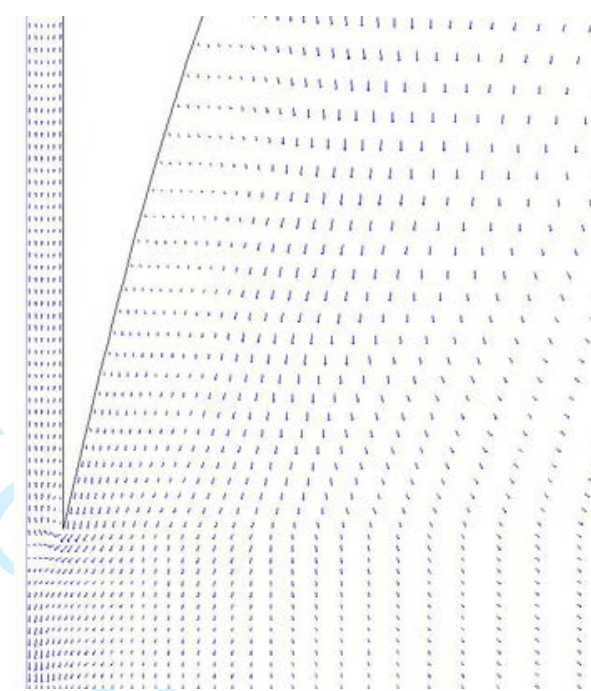

(d): $\mathrm{T}$

Figure 21: Velocity vector $(\mathrm{m} / \mathrm{s})$ at four instants of time during one period after 30 seconds for hyperbolic- sine wedge

The same test cases as for the triangular wedge (Table 2) were run again with the Berkeley wedge wave maker. The first-harmonic $A / S$ ratio is calculated and compared with the results from linear potential flow in Figure 16. In contrast to the simple wedge results, at some frequencies, significant higher harmonic content was found in the wave generated by the Berkeley wedge, as can be seen in Figure 22. Even so, the average $A / S$ ratios for the first harmonic are in a very good agreement with the theory, as can be shown in Figure 16 


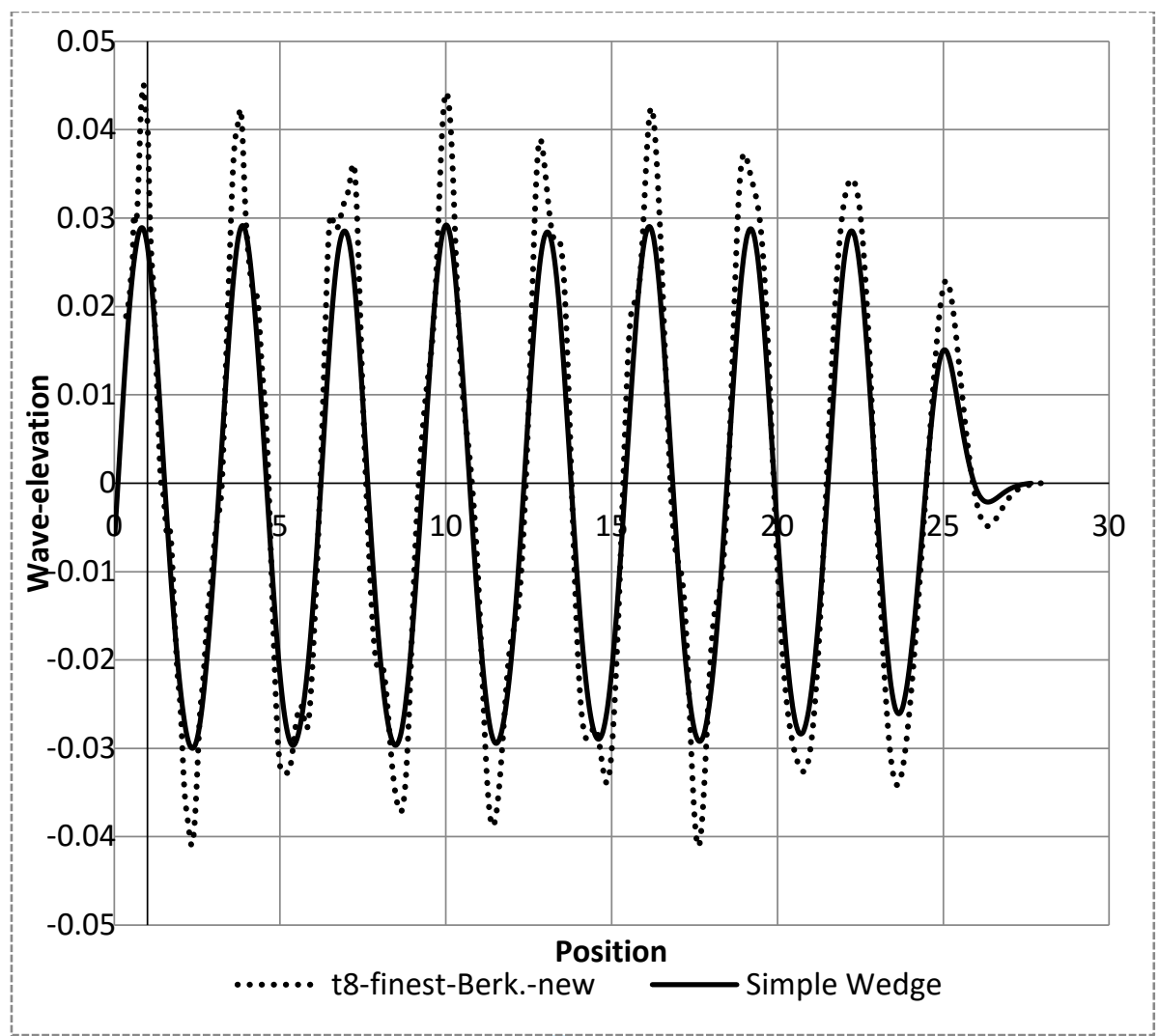

Figure 22: Comparison of wave shape of test case 8 in Berkeley wedge and simple wedge wave-makers

\section{The effect of larger stroke on the wave shape using the Berkeley wedge}

Finally, we consider the effect of larger stroke on the generated wave shape. Four stroke amplitudes were applied to test case 4 as shown in Table 6 corresponding to four different steepness values based on linear theory. The average first-harmonic $A / S$ ratio and the average steepness of these calculations are compared with the results of linear theory in Table 6. It shows that for all stroke amplitudes, the average harmonic $A / S$ ratio matches well with the theory. Figure 23 shows the shape of the waves for each stroke, and the level of higher harmonic content can be seen to increase with wave steepness. With lowering the steepness, the wave shape tends towards a regular sinusoidal shape. However, as noted above, the level of higher harmonic generation tends to be much higher for the Berkeley wedge than for the simple wedge, indicating that this may be a better choice in practice. 
Table 6 : Comparison of $A / S$ ratio and steepness in for different steepness in test case 4 with lambda equal $1.45 \mathrm{~m}$

\begin{tabular}{|l|l|l|l|l|l|}
\hline $\begin{array}{l}\text { Test } \\
\text { Case } 4\end{array}$ & $\begin{array}{l}\text { Total } \\
\text { Stroke } \\
(\mathrm{m})\end{array}$ & $\left(\frac{H}{\lambda}\right)_{\text {Wu-Theory }}$ & $\left(\frac{H}{\lambda}\right)_{\text {Present Work }}$ & $\left(\frac{A}{S}\right)_{\text {Wu-Theory }}$ & $\left(\frac{A}{S}\right)_{\text {Present Work }}$ \\
\hline S0 & .047 & 0.0342 & 0.0341 & 1.058 & 1.09 \\
\hline S1 & .028 & .02042 & 0.02048 & 1.058 & 1.068 \\
\hline S2 & .019 & .01388 & 0.01367 & 1.058 & 1.061 \\
\hline S3 & .0145 & .0105 & 0.0106 & 1.058 & 1.072 \\
\hline
\end{tabular}

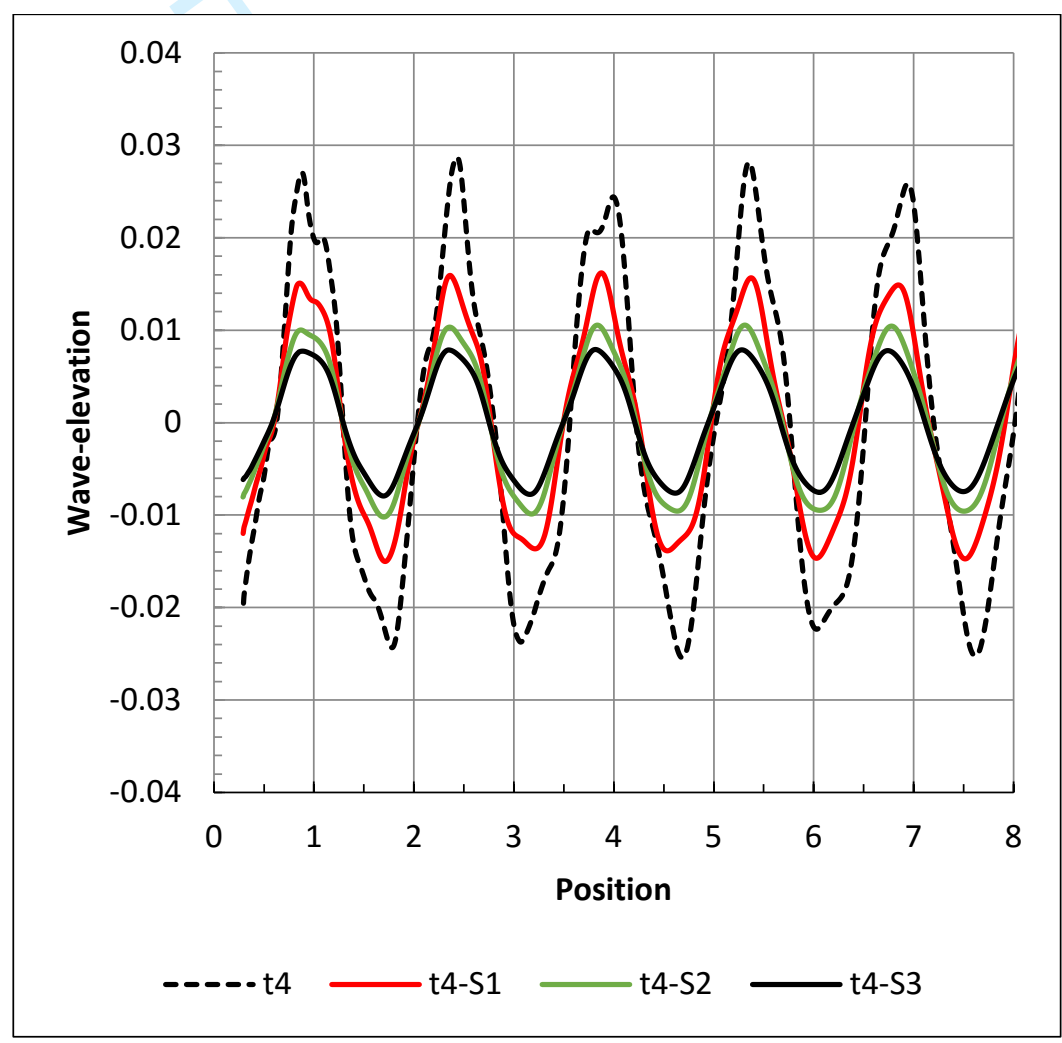

Figure 23: Wave shapes of test case 4 with Lambda equal $1.45 \mathrm{~m}$ with different steepness

\section{Conclusion}

A finite volume, ANSYS-FLUENT code is used to solve the Navier-Stokes equations for the simulation of the flow around a plunger-type wedge shaped wave-maker with a gap between the wedge and the tank wall. An explicit VOF scheme is used to capture the interface in a two-phase flow. The effect of the gap on the generated wave elevation is investigated, and it is concluded that the smallest possible gap behind the wedge is desirable to create good quality waves. 
In addition to a plane triangular wedge, two alternative profiles are tested. For the Berkeley wedge profile, a good agreement with linear potential flow theory is found for the first harmonic amplitude ratio of the wave. For the hyperbolic-sine wedge shape however, very high amplitude waves are generated which do not agree with linear theory. Higher harmonic generation is however found to be a larger problem for the Berkeley wedge than for the simple wedge.

Larger amplitude motions of the Berkeley wedge profile were also tested. The average first harmonic amplitude ratio of the waves for these cases also agreed well with the linear theory, but higher harmonic generation was found to increase rapidly with increasing stroke amplitude.

\section{References}

[1] Prasada D. D., Ahmeda M. R., Leeb Y. H., Sharma R. N.,, "Validation of a Piston Type WaveMaker Using Numerical Wave Tank," Ocean Engineering, vol. 131, pp. 57-67, 2017.

[2] Wang S., "Plunger-type wavemakers: theory and experiment," Journal of Hydraulic Research, vol. 12, no. 3, pp. 357-388, 1974.

[3] Wu Y.-C., "Plunger-type wave-maker theory," Journal of Hydraulic research. Vol. 26, No. 4, 1988.

[4] Wu Y.-C., "Waves generated by a plunger-type wavemaker," Journal of Hydraulic research, vol. 29, no. No. 6, 1991.

[5] Arcari P., "Analysis and optimization of a wedge-type wave generator for the DTU wave," DTU Windenergy, Lyngby, 2015.

[6] Kashiwagi Masashi, "Full-Nonlinear simulations of hydrodynamic forces on a heaving twodimensional body," Journal of The Society of Naval Architects of Janan, vol. 180, pp. 373-381, 1996.

[7] Koo W.C., Kim M. H., "Numerical simulation of nonlinear wave and force generated by a wedge-shape wave maker," Ocean Engineering, vol. 33, pp. 983-1006, 2006.

[8] Mikkola T., "Time accurate simulation of a plunger type wave maker using unstructured finite volume solver with surface tracking,," in 26th Symposium on Naval Hydrodynamics, Rome, 2006. 
[9] Mikkola T., "Simulation of plunger-type wave makers," Journal of Structural Mechanics, vol. 40, no. 4, pp. 19-39, 2007.

[10] Yim S.C., Yuk D., Panizzo A., Di Risio M. and Liu P.L.-F., "Numerical simulations of wave generation by a vertical plunger using RANS and SPH models," Journal of Waterway, Port, Coastal, and Ocean Engineering, vol. 134, no. 3, pp. 143-159, 2008.

[11] Elangovan M. and Lal. A., "Design and simulation of wave maker for marine industry by CFD," in ANSYS India Conference (ANSYS 2008), Bangalore, November 6-7 , 2008.

[12] Elangovan M. and Lal. A., "Simulation and validation of plunger type wave maker by CFD," Journal of the institutuion of engineers (INDIA). Marine engineering division, vol. 91, pp. 1016, 2010.

[13] Gadelho J.F.M., Lavrov A. and Guedes Soares C., "CFD modelling of the waves generated by a wedge-shaped wave maker," Maritime Technology and Engineering, pp. 993-1000, 2015.

[14] Yeung R. W., Jiang Y., "Shape effects on viscous damping and motion of heaving cylinders," Journal of offshore mechanics and arctic engineering, vol. 136, 2014.

[15] Madhi F.,Sinclair M. E. and Yeung R. W., "' The Berkeley wedge' An asymmetrical energycapturing floating breakwater of high performance," Marine Systems \& Ocean Technology, vol. 9, no. 1, pp. 05-16, 2014.

[16] Azadian-Kharanjani Zohre, Nikseresht Amir H., Bingham Harry B., "A numerical investigation of wedge angle effects on a plunger type wave maker with a constant submerged volume," in OMAE 2018, Madrid, Spain, 2018.

[17] Nikseresht A. H., Alishahi M. M. and Emdad H., "Complete flow field computation around an ACV (air-cushion vehicle) using 3D VOF with Lagrangian propagation in computational domain," Computers \& Structures, 2008.

[18] Hicks Jacob B. H., "Development and testing of optimized control signals for a plunger-type wave generator," DTU Mechanical Engineering, Lyngby, 2017. 